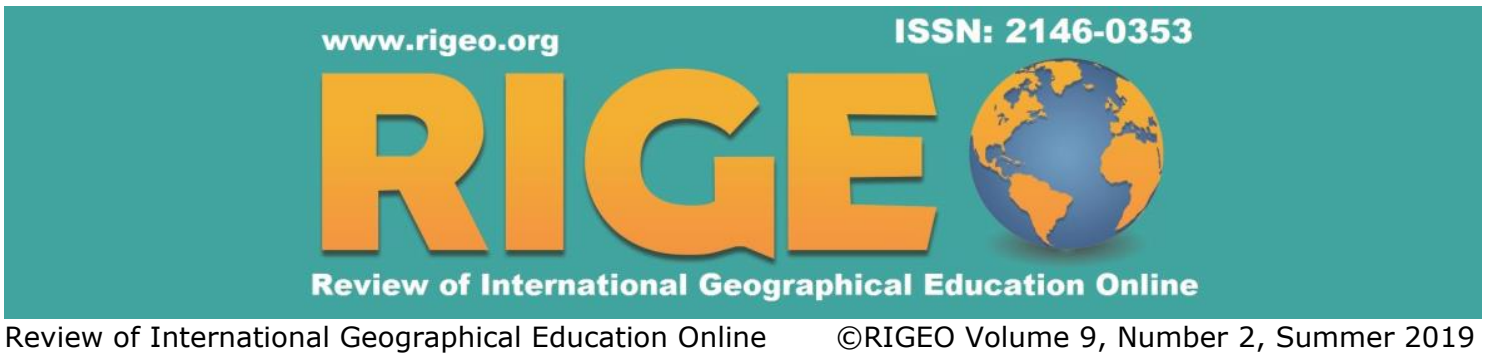

Review Article

Copyright @ RIGEO 2019

To cite this article: Havelková, L., Hanus, M. (2019). Map skills in education: a systematic review of terminology, methodology, and influencing factors. Review of International Geographical Education Online (RIGEO), 9(2), 361-401. Retrieved from http://www.rigeo.org/vol9no2/Number2Summer/RIGEO-V9-N2-6.pdf

DOI: 10.33403/rigeo.591094

Submitted: June 27, 2019 Revised: July 20, 2019 Accepted: 16 August 2019

\title{
Map Skills in Education: A Systematic Review of Terminology, Methodology and Influencing Factors
}

\author{
Lenka HAVELKOVÁ 1 \\ Charles University, Prague, CZECHIA \\ Martin HANUS ${ }^{2}$ \\ Charles University, Prague, CZECHIA
}

\begin{abstract}
For a few decades, map skills stay at the forefront of not only geographers' and geographic educators' research interest. To identify what has already been accomplished, where the research currently stands and where the potential for future studies lies, a review of the literature was carried out. Specifically, this comprehensive synthesis of map skill research focuses on three perspectives: terminology, methodological approaches, and mainly on investigated factors affecting the map skill level. As nonuniformity in terminology is apparent, an integrative framework of map skill types based on theoretical works and previous studies is proposed. Similarly, methods that can be more suitable and beneficial for future research than now prevailing non-standardized test are presented. These suggestions are mainly based on a variety of identified scarcely used methodological approaches. Furthermore, the synthesis shows that the number of factors which influence on the level of map skills has been tested is substantial. But that, frequently investigated categories of factors are identifiable. In addition, current gaps in map skill research are identified and insufficiently studied, yet potentially important factors are suggested for future studies.
\end{abstract}

Keywords

Map Skill; Map Reading; Map Use; Geography Education; Systematic Review

\footnotetext{
${ }^{1}$ Corresponding author: PHD Candidate, Charles University, Faculty of Science, Department of Social Geography and Regional Development, Centre for Geographical and Environmental Education, Albertov 6, 128 00, Prague 2, Czechia, I.havelkova[at]natur.cuni.cz, ORCID: 0000-0002-6266-4801

${ }^{2}$ Assistant Professor, Charles University, Faculty of Science, Department of Social Geography and Regional Development, Centre for Geographical and Environmental Education, Albertov 6, 128 00, Prague 2, Czechia, martin.hanus[at]natur.cuni.cz, ORCID: 0000-0002-9873-5106
}

(C) Review of International Geographical Education Online RIGEO 2019 ISSN: 2146-0353 
The current period can be characterised as spatial information age. The development and increased accessibility of modern technology mean that we are confronted every day with a huge amount of information about objects, phenomena and processes, and their spatial perspective. This would have been unthinkable just one hundred years ago (LaSpina, 1998).

One of the frequent methods used to visualise spatial information is a map. Its popularity is largely due to its potential for visualising spatial distribution of selected information which can put the information in a completely new perspective (van Dijk, van der Schee, Trimp, \& van der Zijpp, 1994). The ever-present popularity of maps has risen to such an extent that it is possible to find them almost everywhere, as the World Wide Web has dramatically transformed the way in which they are created and distributed (Ooms et al., 2015). Publicly accessible geographic applications and geographic information systems have also been of great significance for the dissemination of maps in recent years. As such, the public not only uses maps, but also frequently creates them (Hamerlinck, 2015; Hurst \& Clough, 2013; Pedersen, Farrell, \& McPhee, 2005).

The increasing popularity of maps together with the development of cartography as a science has led to a greater need to develop students' map skills, i.e. skills associated with use and drawing of maps. The more skilful people are in using maps, the better they will be able to interpret spatial information about both the globe itself and the place where they live. Consequently, it will also be easier for them to make sense of the world (Catling, 2005; Gökçe, 2015; Hanus \& Havelková, 2019; Harte \& Dunbar, 1994).

Moreover, map skills are a substantial part of geographical competence that can address many employers' needs in the business, government, and non-profit sectors, as well as in the geospatial technology industry (DiBiase et al., 2010; Schulze, Kanwischer, \& Reudenbach, 2011; Solem, 2017; Solem, Cheung, \& Schlemper, 2008). Map skills and related spatial thinking together with GIS use are three of the four areas of geographical skills most needed at work according to geography alumni (Schlemper, Adams, \& Solem, 2014; Solem, 2017; Solem et al., 2008).

The need for the development of map skills, inter alia, has increased pressure on research in the field. In approx. the last 40 years, a number of studies have been published describing the level of map skills and identifying independent variables (hereinafter referred to as factors) that affect this level. These studies, however, are characterized by a considerable variety of terminology and a quite unsystematic (from the perspective of the overall state of knowledge in the field) selection of methodological approaches, sample characteristics and factors investigated. This causes difficulties for the generalisability of knowledge, the planning and implementation of further research aiming at providing a comprehensive understanding of the current level of map skills, and for an understanding of map development processes.

Therefore, the main goal of this study is firstly to address these difficulties and to synthesise prior research in the field of map skills, as it reveals the current state and the main trends; and, secondly to offer guidance to researchers who are seeking suitable unanswered questions regarding map skills and the factors affecting their level of 
development. As there has been no systematic review of the literature focusing on map skills in general, the following research questions are addressed:

- How are map skills defined by individual researchers?

- What types of map skills and what specific operations with maps are commonly investigated?

- What methodological approaches are used to identify the level of map skills?

- What factors have been most frequently tested as potentially affecting the level of map skills?

- Does the research attention dedicated to these factors correspond to the overall results of the studies?

- What potentially relevant factors have not yet been (sufficiently) studied or have an influence which has yet to be well understood?

A systematic review of literature published from 1980 to 2016 was carried out and a narrative synthesis of the results is employed to address these questions. To make the synthesis systematic and comprehensive, an elementary framework of map skills classification and of types of factors influencing map skills is discussed.

\section{Theoretical Framework}

\section{Map Work and Map Skills}

Map work consists of the understanding of map concepts and the practising of map skills which people employ when working with or drawing maps (Hanus \& Havelková, 2019). However, a study of the literature has shown specification of map skills to be problematic. Authors (Board, 1978; Herrmann \& Pickle, 1996; Keates, 1996; Kimerling, Buckley, Muehrcke, \& Muehrcke, 2009; McClure, 1992; van Dijk et al., 1994; Wiegand, 2006) differ on which operations should be included among map skills. However, it can generally be stated that map skills can be broadly differentiated into activities associated with map use and activities associated with map drawing (Drumheller, 1968; Gerber, 1984; Harwood \& Usher, 1999). Map use can be further specified based on operations corresponding to the reading, analysis and interpretation of maps (Carter, 2005; Kimerling et al., 2009; Liebenberg, 1998; van Dijk et al., 1994; Wiegand, 2006).

The individual types of map use skills have been appropriately described by (Wiegand, 2006, p. 111):

Map reading is characterised as simply extracting information from the map. Map features are identified and named and their attributes noted. Map analysis involves processing that information in order, for example, to describe patterns and relationships or to measure distances between places. Map interpretation goes beyond what is shown on the map and involves the application of previously acquired information in order to solve problems or make decisions.

Hanus \& Marada (2014) in association with Board (1984) have, moreover, emphasized the fact that higher-order (more complex) map skills incorporate those from lower levels (less complex, with lower cognitive demands). Specific operations 
representing the subject of research in the studies reviewed have been assigned to the above-defined map skills to narrowly specify them (see Figure 1). This approach to map skill categorization fully reflects the current concept of working with maps as tools for developing geographic thinking (Hanus \& Havelková, 2019). Therefore, it is used to categorize studies and interpret the results of this systematic review.

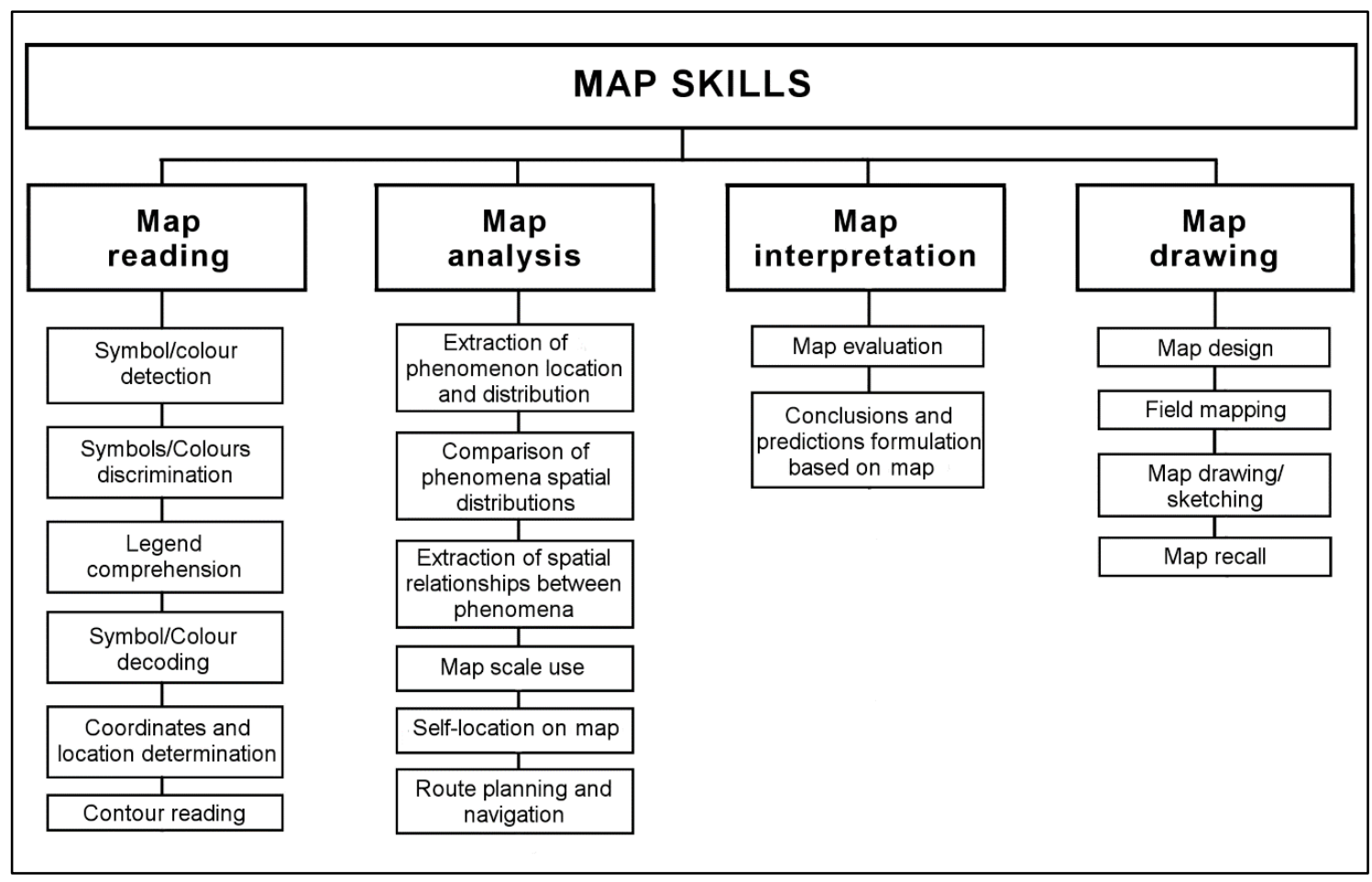

Figure 1. Map skill categorization.

Source: compiled on the basis of Drumheller (1968); Hanus \& Marada (2014); Herrmann \& Pickle (1996); Keates (1996); Kimerling et al. (2009); Riding \& Boardman (1983); Rittschof, Griffin, \& Custer (1998); Robinson (1995); Wiegand (2006).

\section{Factors Affecting Map Skill Level}

It is possible to designate basic categories of factors (i.e., independent variables) which may influence map skill level and its development based on the concept of cartographic communication (Koláčný, 1969; Wood, 1972) or eventually on the concept of cartographic interaction (Roth, 2012). Although the concept of cartographic communication has already been superseded in terms of the mediation of cartographic information, the categorization of factors influencing map skills is still appropriate.

This involves factors associated with the map itself (map characteristics) on the one hand and factors, i.e., attributes, associated with the map user (user characteristics) on the other hand. These two categories should be supplemented with a third, which includes the characteristics of the social, learning, etc. environment (external factors). As the cartographer's creation of a map and, particularly, the map user's work with a map can be impeded or promoted by them (e.g., home environment, familiarity with the area, teacher's learning style). 


\section{Methodology}

\section{Research Design}

This study reviewed both experimental and correlational empirical studies which have tested map skill level and its dependence on an independent variable (factor). The review intentionally concentrated on studies with participants of school age (including university and college students), older than five years, as a high degree of variance in the tested and significant factors is to be expected in the case of preschool children due to their level of cognitive development and due to the frequent fundamental differences in research design (e.g., Blades et al., 1998; Liben \& Yekel, 1996; Sowden, Stea, Blades, Spencer, \& Blaut, 1996). For the same reason, studies which specifically only concentrate on participants with special educational needs, i.e., participants with learning disabilities, blind/deaf participants, participants with behavioural disorders etc. were not considered (e.g., Fox \& Avramidis, 2003; McKissick, Spooner, Wood, \& Diegelmann, 2013; Pike, Blades, \& Spencer, 1992).

\section{Literature Search}

A broad literature search was carried out for peer-reviewed articles which tested map skill level and investigated at least one factor which could explain differences in this level between individual participants or groups of participants. The systematic review was performed according to the Preferred Reporting Items for Systematic reviews and Meta-Analyses (PRISMA) criteria, a systematic and explicit method for identifying, selecting, and critically appraising relevant research. PRISMA consists of a 27-item checklist and a four-phase (Identification, Screening, Eligibility, Included) flow diagram (Moher, Liberati, Tetzlaff, Altman, \& The PRISMA Group, 2009).

Keywords, titles and abstracts of peer-reviewed articles published in English between $1980^{3}$ and 2016 were searched for in two major electronic bibliographic databases most relevant to the investigated research field, namely Scopus and the Education Resources Information Center (ERIC). The following keyword combinations were used:

("map skill" OR "map reading" OR "cartographic skill" OR "map interpretation" OR "map understanding" OR "map use skill" OR "mapping skill") AND ("testing" OR "level" OR "children" OR "pupil" OR "student").

Due to the focus on map skills and its educational aspects, the Scopus search was further refined by subject area, specifically to the Arts and Humanities, Computer Science, Earth and Planetary Sciences, Environmental Science, Mathematics, Psychology and the Social Sciences. The search process resulted in 563 potentially relevant articles after excluding 59 duplicates (Figure 2). A subsequent search of reference lists was not conducted as retrieving literature by scanning reference lists may produce a biased sample of studies (Higgins \& Green, 2011).

\footnotetext{
${ }^{3}$ The studies published prior to the year 1980 were not taken into consideration as the preliminary search had shown their prevailing different research aims and perspectives. Specifically, the found empirical studies were more focused on a map and its design than a map user and map user's skills. Alternatively, the articles concentrated on suggesting effective development and learning of map skills without conducting (rigorous) research.
} 


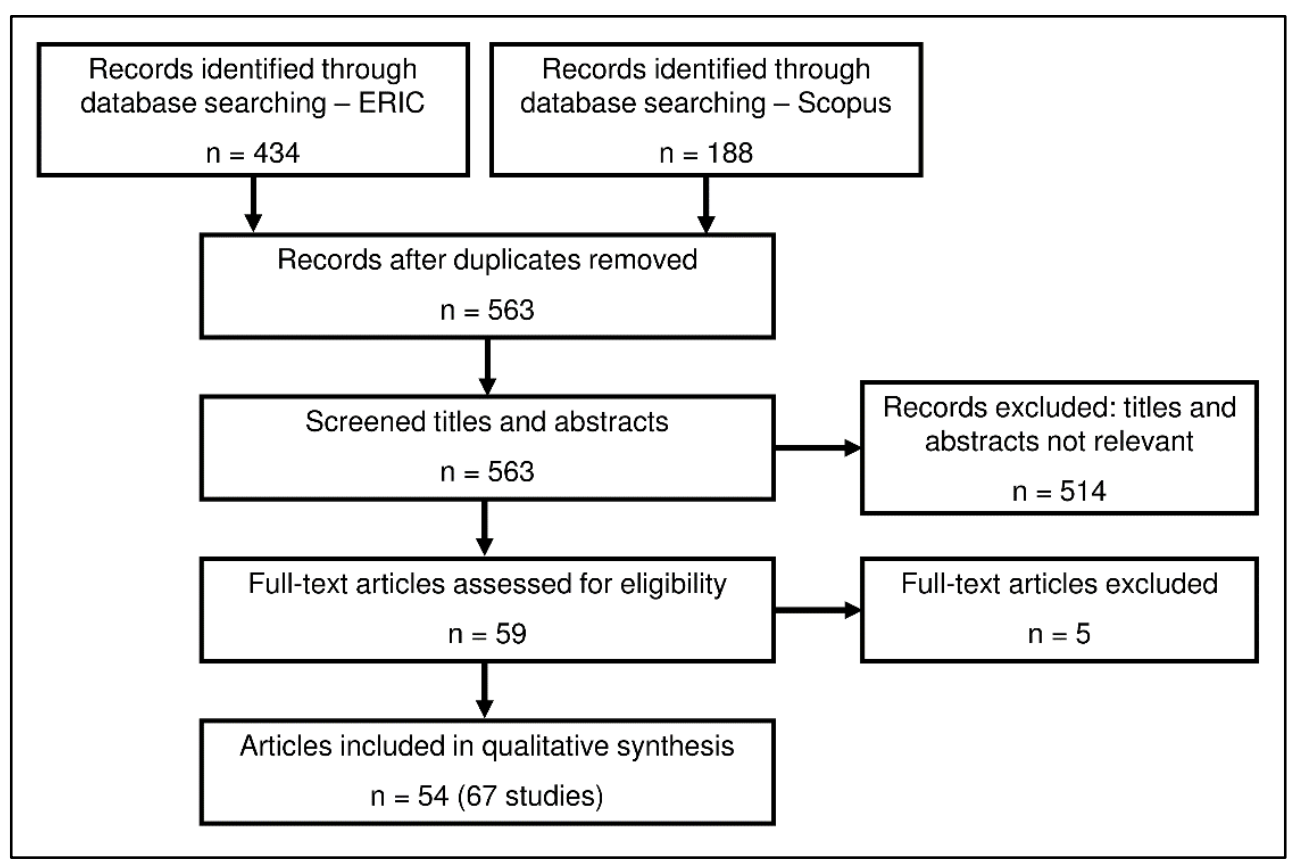

Figure 2. Flow of the studies for inclusion in the review.

In the second stage, both authors independently inspected the identified article titles and abstracts and confirmed that the selected articles:

(1) did not involve participants younger than 6 years of age or participants with special educational needs;

(2) tested the level of at least one map skill and the influence of at least one factor on it;

(3) provided empirical evidence or evaluation;

(4) were written in English.

In the case of conflict of the criteria or disagreement, the full paper was obtained and independently inspected and the inclusion criteria were applied. Any disagreement between the authors was resolved through discussion and consensus. In the end, 54 papers were identified as the research sample pool for this review (see Figure 2). Noticeably, some papers involved more than one study. In order to differentiate between the variants of empirical approach (choice of type of map skills and factors tested), each study was counted separately. As a result, a further 13 studies were identified for a total of 67 studies, of which 38 were correlational studies and 29 were experimental studies (see Appendix). A more detailed description of the electronic database searches can be obtained from the authors.

\section{Data Extraction}

A structured data extraction form was used onto which both authors abstracted data from each included article The authors abstracted data concerning the main characteristics of the empirical studies relevant to the aims of the review: sample size, participant age, map skill(s) tested, research methods, factor(s) considered to affect map skill(s) level, and main outcomes concerning statistically significant factor(s) and how 
it/they influenced map skill level. An extensive table showing the data abstracted from each reviewed paper is listed in the Appendix.

\section{Data Synthesis}

The aim of the data synthesis process was to integrate, based on the stated research goals, the results from the various types of primary research (i.e., from the perspective of the definition of map skills, the methodological approach, the map skill(s) tested, and the factor(s) considered). However, statistical synthesis of the results was prevented by the excessive heterogeneity of the experimental and correlational studies and sometimes insufficiently described methodology and results, described in more detail below. Narrative synthesis is therefore employed.

Table 1

Main categories, Subcategories and Number of Identified Factors

\begin{tabular}{llr}
\hline Main category & Subcategory & \# Factors \\
\hline User characteristics & age & 2 \\
& ethnicity and culture & 4 \\
& gender & 1 \\
& geographical knowledge and skills & 15 \\
& individual disabilities & 3 \\
& leisure and hobbies & 7 \\
& non-geographical abilities and skills & 10 \\
Map characteristics & psychological factors & 14 \\
& cartographic means of representation & 6 \\
& complexity & 7 \\
External factors & other & 5 \\
& education & 3 \\
& family & 3 \\
& tested map skill & 1 \\
& residence & 1 \\
& teaching & 11 \\
\hline
\end{tabular}

In addition to summary narrative text and tables, data were also synthesized into conceptual maps, i.e., diagrams depicting relations between concepts and, eventually, the strength of these relations. In this article, the conceptual maps describe and clearly show the major factors influencing map skill levels and the relations between factor influence and type of map skill tested. Therefore, the number of studies testing a given factor's influence was counted for each factor, as was the number of studies in which the factor's influence was statistically significant/or tested but not statistically significant.

Furthermore, the factors were categorised as relating to one of user characteristics, map characteristics or external factors. The categories were further divided by the authors into subcategories representing and characterizing the different types of factors, more suitable for conceptual maps and synthesis of results (see Table 1). Given the 
chosen synthesis process and the main aim of this review, the conceptual maps omit any identified factor not proven to be significant in at least one study (see Table 2).

Table 2

Not Statistically Significant Factors

\begin{tabular}{ll}
\hline Factor & Main category \\
\hline Colour blindness & User characteristics \\
Dyslexia & User characteristics \\
Feeling of task importance & User characteristics \\
Hemisphericity & User characteristics \\
Hobby preferences & User characteristics \\
Interest in maps & User characteristics \\
Possibility of teaching career & User characteristics \\
Reading of geographical magazines & User characteristics \\
Score in language test & User characteristics \\
TV viewing & User characteristics \\
Watching geography programmes & User characteristics \\
Youth club membership & User characteristics \\
Digital/paper map & Map characteristics \\
Symbol type & Map characteristics \\
Familiarity of materials & External factors \\
Parental education & External factors \\
Parents travelling abroad & External factors \\
\hline
\end{tabular}

The conceptual maps were created using Gephi graph visualization and manipulation software. More specifically, Gephi's ForceAtlas layout was used as it can cluster related nodes, and move strongly connected nodes to the centre of the conceptual map and less connected nodes to its boundaries. Nodes represent the significant factors, the subcategories and categories they fall under, and the type of map skill tested. The weight of each node (its size) is based on the number of studies in which the influence of the factor on map skill level was proven to be significant. The same applies to edges (links) representing the existence and strength of a relation between two nodes (based on the number of studies in which the relation has been found significant). The clarity of the conceptual maps has been increased by colourising nodes and links according to the aforementioned categorisation of the factors.

\section{Findings and Results \\ Differences in Terminology and Definition of Map Skills}

Synthesizing current research base from the point of view of the terminology used for the skills participants employs when using or drawing maps has proven difficult. Some authors do not use any specific terms at all, because they place these skills within a broader group of skills, e.g., geographical skills, geospatial thinking skills, spatial (reasoning) skills (Battersby, Golledge, \& Marsh, 2006; Beatty \& Tröster, 1987; Kelly, Kelly, \& Miller, 1987; Liben, Myers, Christensen, \& Bower, 2013; Logan, Lowrie, 
\& Diezmann, 2014). Other authors admittedly distinguish between these skills, but do not further specify their terminology, making comparisons impossible (Bein, 1990; Bein, Hayes, \& Jones, 2009; Henrie, Aron, Nelson, \& Poole, 1997; Lim, 2005; Livni \& Bar, 2001; Nelson, Henrie, Aron, \& Poole, 1996; Scevak \& Moore, 1998; Shin, 2007).

Nevertheless, it was quite clear from the other studies that authors differ even in their overall designations of these skills. In addition to the term "map skills", there can also be found in the literature, for example, "mapping skills (abilities)" (Aksoy, 2013; Baker, Petcovic, Wisniewska, \& Libarkin, 2012; Matthews, 1986; Trifonoff, 1995) and "cartographic skills" (Grofelnik \& Pap, 2013). An even greater variety of terms arises in the case of individual operations. As mentioned in the introduction to this review, authors do not agree on which operations fall under "map skills" or even on how to categorise them. In addition to the division into "map reading", "map analysis", "map interpretation" and "map drawing", other terms are used, such as "map understanding/comprehension" (Allen, Miller Cowan, \& Power, 2006; Clark et al., 2008), "wayfinding/navigation skills" (Alhosani \& Yagoub, 2015; Johnson, Johnson, Stanne, \& Garibaldi, 1990; Malinowski \& Gillespie, 2001) and "map learning/recall" (Postigo \& Pozo, 1998, 2004; Winn \& Sutherland, 1989). However, these terms refer to specific operations with maps which can be assigned to the types of map skills mentioned above.

From a researcher's perspective, the number of terms used impedes the search for relevant published studies and increases the definitional redundancy of some terms. For example, a substantial number of authors use "map reading (skill)" for all map use skills, including map analysis and map interpretation (Barker, Hailstone, \& Simmonds, 1986; Chang \& Antes, 1987; Ishikawa, 2016; Ooms et al., 2015; Riding \& Boardman, 1983; Umek, 2003).

\section{Map Skills Tested}

It is apparent from the previous text that it was necessary to re-categorise studies included in the review by map skill(s) tested in order to answer the research questions. Wiegand's (2006) definition of map skill types and the detailed schema of individual operations with maps (Figure 1) were used to unify the terms. Studies focusing on multiple types of map skills were assigned to all types tested in it.

Thanks to this synthesis, it was discovered that the studies most frequently tested the ability to read a map (59\% of studies) followed by map analysis (47\%) and map drawing (27\%), while studies testing map interpretation were rarest (19\%). No study was oriented solely towards this ability. Map interpretation was tested in participants in association with their ability to read or analyse maps (Allen et al., 2006; Chang \& Antes, 1987; Hanus \& Marada, 2016; Ishikawa, 2016; Liebenberg, 1998; Pedersen et al., 2005). This connection is also apparent from Figure 5 which depicts factors with significant influence on given types of map skills.

Of the specific operations, the most popular were without doubt route planning, navigation and self-location on a map (Aksoy, 2013; Alhosani \& Yagoub, 2015; Griffin, 1995; Griffin \& Griffin, 1996; Hemmer et al., 2013; Lim, 2005; Logan et al., 2014; 
Malinowski \& Gillespie, 2001), which fall under map analysis skills. In contrast, numeric map scale use, another map analysis skill, was rarely tested (Aksoy, 2013; Grofelnik \& Pap, 2013; Hanus \& Marada, 2016; Hemmer et al., 2013). The individual operations constituting map interpretation and drawing skills (see Figure 1) have been researched similarly often.

Although map reading skills were most frequently researched, substantial differences are apparent in the frequency of research into individual map reading skill. For example, ability to determine geographic coordinates was researched only by Aksoy (2013) and Grofelnik \& Pap (2013). While, in contrast, research focused very frequently on symbol and colour discrimination and decoding (Alhosani \& Yagoub, 2015; Barker et al., 1986; Gilmartin \& Shelton, 1989; Ishikawa, 2016; Liebenberg, 1998; Ooms et al., 2015) and on the locating objects on a map (Beatty \& Tröster, 1987; Clark et al., 2008; Eve, Price, \& Counts, 1994; Hemmer et al., 2013; Kastens \& Liben, 2010).

Some authors do not take differences between individual subsets of map skills into account in their empirical studies and state that their goal is to identify general level of map skills (Bein, 1990; Bein et al., 2009; Grofelnik \& Pap, 2013; Henrie et al., 1997; Kelly et al., 1987; Livni \& Bar, 2001; Nelson et al., 1996). Nevertheless, their research tasks are sometimes closely associated with one specific type of map skill or even only a few specific operations. The failure to differentiate between individual skills may arise from the different research focuses of the authors, as a result, sufficient awareness of map skill diversity may be lacking. This substantially precludes identification of overall map skill level other than via a single robust research tool or the combination of several research tools.

\section{Methodological Approaches to Map Skill Testing}

As with the map skill concepts, not all studies give sufficient information about methodological approaches chosen to test the level of the map skills and identify factors influencing (Bein, 1990; Bein et al., 2009; Gerber, 1984; Nelson et al., 1996). As such, these insufficient descriptions indicate a high risk of bias and therefore substantially reduce not only the methodological but also overall quality, even when the studies make use of a suitable approach and create a valuable research instrument(s).

The absence of a used research instrument is also problematic not only for evaluating the quality of the studies, but also for research continuity with previous studies and comparing results (Matthews, 1986; Postigo \& Pozo, 2004; Riding \& Boardman, 1983; Umek, 2003). Instead of a used instrument, the articles often include examples of tested items, either only a few or an entire battery of questions, but without the maps which participants were supposed to use to answer them (Alhosani \& Yagoub, 2015; Henrie et al., 1997; Kelly et al., 1987; Pedersen et al., 2005; Postigo \& Pozo, 1998).

Generally, however, there are no substantial differences in the research instruments used, because suitable use of tests or questionnaires consisting of tasks/questions and maps usually suffices to identify most map skills and it is therefore not surprising that they predominate (e.g., Chang \& Antes, 1987; Clark et al., 2008; Michaelidou, Nakos, \& Filippakopoulou, 2004; Ooms et al., 2015; Teck, 1989; Trifonoff, 1995; van Dijk et 
al., 1994). Tests and questionnaires are often created by the authors based on theoretical knowledge or curriculum requirements, but there are also studies which have made use of preexisting and therefore tested tools (Aksoy, 2013; Hemmer et al., 2013; Sholl \& Egeth, 1982; Ugodulunwa \& Wakjissa, 2015; van der Schee \& van Dijk, 1999).

The only case where tests do not prevail involves identification of map drawing level. Instead, participants were required to draw a map ranging from a sketch (mental) map (Harwood \& Usher, 1999; Matthews, 1986; Postigo \& Pozo, 1998; Shin, 2007) to a contour map (Wiegand \& Stiell, 1997) and on to a map of a real environment base on field research (Baker et al., 2012). Exceptionally, studies were found which made use of audio or video recordings or the interview or think-aloud method to identify map skill level (Leinhardt, Stainton, \& Bausmith, 1998; Logan et al., 2014; Ungar, Blades, $\&$ Spencer, 1997). These methods were mainly used in combination with other aforementioned methods (test, map drawing).

The distribution of research methods used to identify factors influencing map skill levels is highly similar to the above. Factors characterising map users are ascertained almost exclusively using questionnaires (e.g., gender, age, grade, liking for geography and marks for school subjects) or tests (e.g., spatial ability, maths skills, cognitive/learning style and drawing ability). The influence of factors falling under map characteristics (e.g., map type or figure-ground contrast) and external factors (e.g., teaching method or type of pre-test instruction) is predominantly verified in experimental studies (Barker et al., 1986; Bausmith \& Leinhardt, 1998; Griffin, 1995; Johnson et al., 1990; Ungar et al., 1997; van der Schee \& van Dijk, 1999). The method of identifying them therefore corresponds directly with the methodological approach selected for testing map skill level.

The designated research sample is also important for interpreting the influence of the chosen factors on map skill level. The studies differ crucially in size of research sample. The sample size (just like the sample structure) is substantially influenced by the research method and the focus of the study. As such, there are studies (24\% of studies) which ascertained map skill level and verified the influence of researched factors in less than 50 participants (e.g., Bausmith \& Leinhardt, 1998; Hirsch \& Sandberg, 2013; Ishikawa, 2016; Kastens \& Liben, 2010; Liben et al., 2013; Shin, 2007; Ungar et al., 1997). The transferability and generalisability of the results ascertained are therefore substantially limited because both map skill level and influence of researched factors could be substantially influenced by unascertained specifics of individual participants. Nevertheless, these studies can still be of great importance for the research field when they use qualitative research methods and aim to study students' development and level of a specific map skill in depth.

Moreover, a high number of participants (more than 600) does not necessarily mean simpler interpretation and greater transferability of results from the point of view of map skills and factors influencing them. As for example in case when the selected research tool is insufficiently described or contains only a few test items associated with map skills because it is more widely focussed, e.g., on geographical skills generally 
(Beatty \& Tröster, 1987; Bein, 1990; Gerber, 1984; Henrie et al., 1997). The sample size is stated for all studies in the Appendix.

\section{Factors Affecting Map Skill Level}

As most of the studies investigated the influence of more than one factor, a total of 93 different factors were identified. The influence of most factors (66\%) was, however, investigated only once. The substantial variety of selected factors and particularly the considerable representation of factors tested only once contributes to the number of factors (18) which influence has not been proven in any study (see Table 2). These factors are not included in Figures 3 and 5 as they display only the factors affecting map skills (i.e., 75 factors) ${ }^{4}$.

As far as the main categories of factors are concerned, authors most frequently verified the dependency of map skill level on factors characterising map users $(81 \%$ of the studies), followed by external factors (64\%), with the influence of map characteristics investigated least frequently $(25 \%)$. The distinct predominance of factors characterizing map users is even more apparent if their weights are totalled, i.e., the number of studies in which their influence has been proven (see Figure 3). This high degree of representation is caused substantially by the higher number of identified factors aiming to describe participants (57 out of 93). By comparison, the number of factors aiming to describe map characteristics is almost the same as the number of external factors (17 vs 19), yet the number of studies focused on them and verifying their influence differs substantially (see Figure 3).

Figure 3 also clearly shows which identified factors have been most frequently proven as affecting level of map skills (gender, age, map skill tested, grade, expertise in geography, spatial ability and teaching method) and similarly which of the subcategories created for the purposes of this review (geographical knowledge and skills, teaching, non-geographical abilities and skills, age, gender and psychological factors).

A substantial variety of statistically significant factors is noticeable particularly in the subcategory of psychological factors (see Figure 3). Not only have the previous studies verified the influence of certain types and parts of intelligence (verbal, nonverbal, general verbal reasoning), they have proven other mental processes to be influential (e.g., motivation, emotion, memory).

\footnotetext{
${ }^{4}$ The specifics of influence of individual factors as well as for example the specific age group for which the factors have been proven to be significant is not in detail described in the article. As its aims are different and it is out of scope of single article to do so. Nevertheless, this information are part of the Appendix which comprehensively sum up main outcomes of reviewed studies.
} 


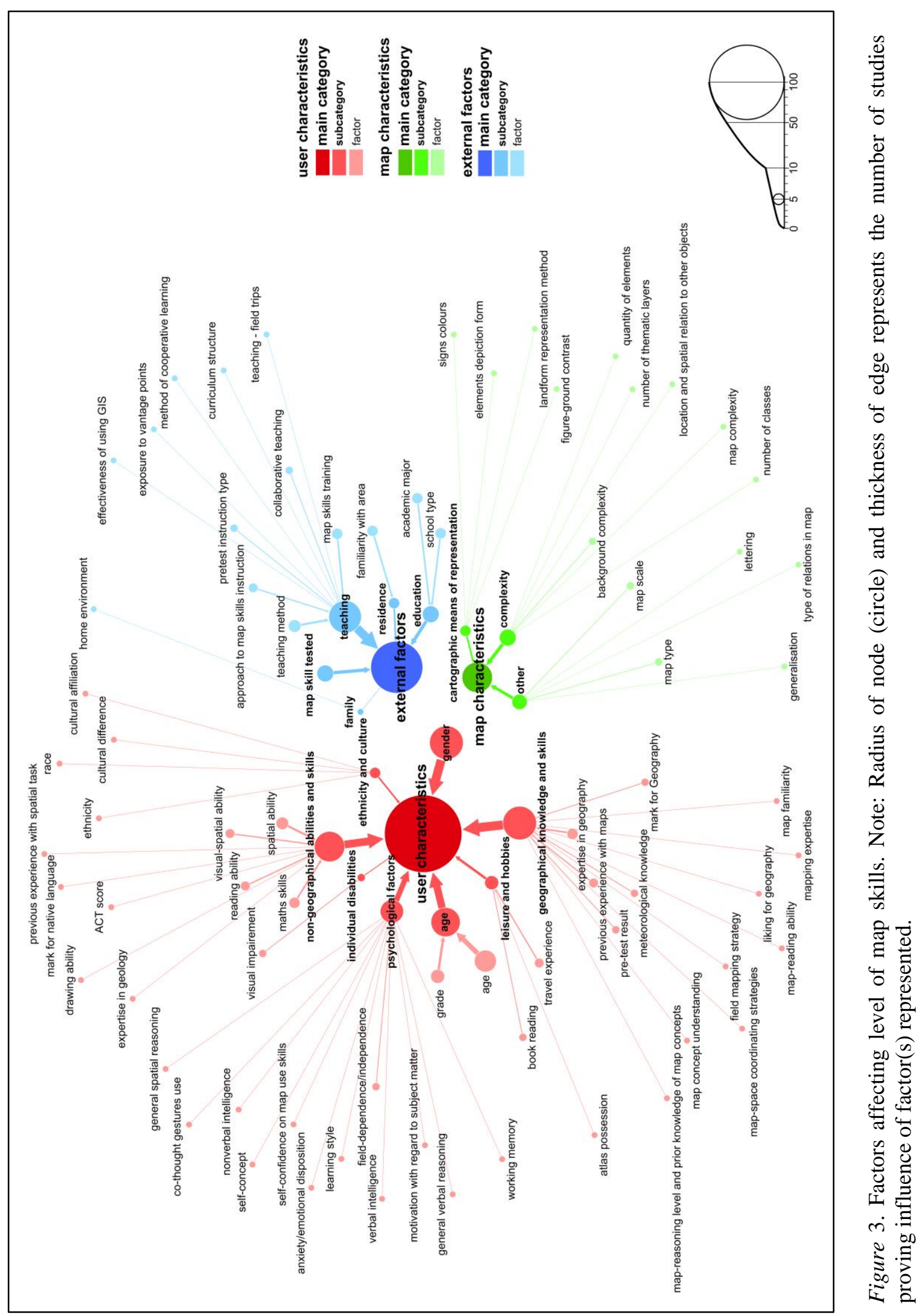


On the contrary, the subcategory of geographical knowledge and skills is rather uniform despite the number of factors it includes. The majority of them characterize knowledge and skills directly linked to cartography. Meteorological knowledge is the only proven (and also tested) specific factor related directly to one of the main geographical branches. Similarly, the math-related abilities and skills prevail among the statistically significant factors belonging to non-geographical abilities and skills.

Clarity of factors influence. Nevertheless, the unequivocal nature of the influence of the researched factors cannot be evaluated simply upon the basis of the number of studies which demonstrate the dependency of map skill level on them. After all, this number is substantially influenced by the number of authors who have decided to verify the influence of the given factors in their research. As such, factors, which are easy to identify within the framework of a study, or factors which influence is debatable from the point of view of previous theoretical and empirical studies, may appear relatively frequently.

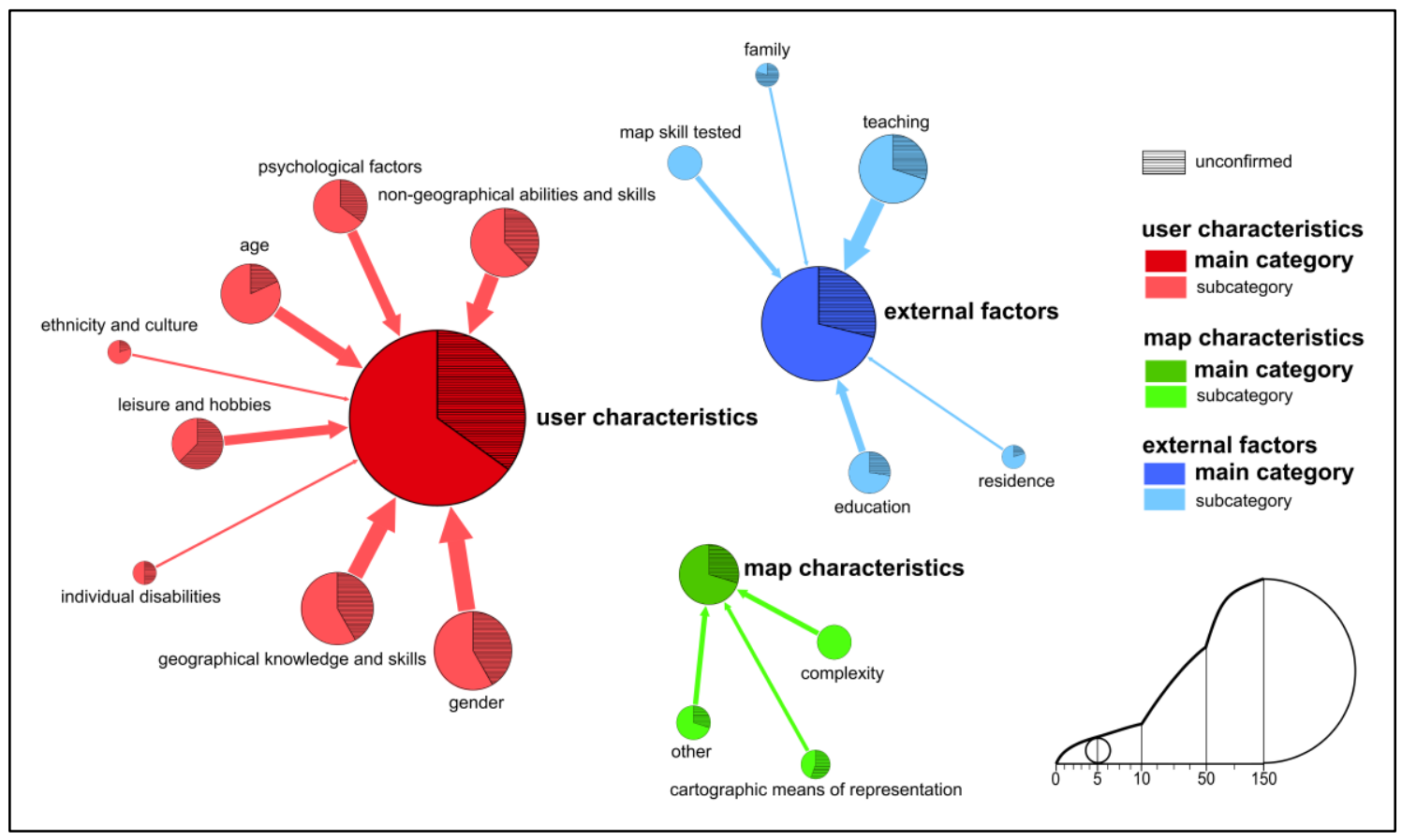

Figure 4. Structure of factor categories according to demonstration of their influence.

Note: Conceptual map includes all 93 identified factors. Radius of node (circle) represents the number of studies testing influence of factor(s) represented. Thickness of edge represents the number of studies proving influence of factor(s) represented.

Gender is a suitable example of such a factor. See Figure 4 above, which depicts in diagrams (using a grid) the share ${ }^{5}$ of studies per identified subcategory which have not proven the influence of factors on map skill level. As is already clear from Table 3, the

${ }^{5}$ This share of the studies is not related to the overall number of studies in which the influence of the given factors was verified. In some studies, the influence of the given factor was only partially proven (e.g. only for one map type, only for some test tasks) and these cases were included among both the statistically significant and statistically insignificant factors (it was counted twice; see Table 3). 
influence of gender on map skill level has been only partially proven in the large share of studies dealing with it. For example, the results of Chang \& Antes (1987) study show that males performed significantly better than females in reference and topographic map use, but not in street map use. At odds with many other studies which found that male participants had a higher level of map skills than female participants (Eve et al., 1994; Hemmer et al., 2013; Lim, 2005; Malinowski \& Gillespie, 2001), Aksoy (2013) found either no differences between male and female participants or that some operations falling under map reading were significantly in favour of female participants. Considered together, therefore, the results of the studies show that gender interacts with other factors which should be taken into account both when designing the study and when interpreting and comparing the results.

It is also apparent from Figure 4 that the debatable nature of factors' influence does not involve only the factor of gender. Subcategories of factors with an even higher share of studies in which their influence at the level of map skills is not significant can be found (leisure and hobbies, cartographic means of representation and individual disabilities). Nevertheless, unlike gender, they involve factors which have been investigated less frequently.

Table 3

Factors Which Influence Has Been Proven in 5 or More Studies

\begin{tabular}{lllll}
\hline Factor (Main Category) & \# Studies & \# Significant & \# Unconfirmed & Subcategory \\
\hline Gender (U) & 27 & 18 & 15 & Gender \\
Age (U) & 13 & 12 & 3 & Age \\
Tested map skill (E) & 8 & 8 & 0 & Map skill tested \\
Spatial ability (U) & 7 & 5 & 4 & Non-geographical \\
Grade (U) & 6 & 6 & 1 & abilities and skills \\
Teaching method (E) & 5 & 5 & 2 & Age \\
\hline
\end{tabular}

Note: In some studies, the influence of the given factor was only partially proven (e.g., only for one map type, only for some test tasks) and these cases were included among both the statistically significant and not statistically significant (unconfirmed) factors. Legend: U - User characteristics, E-External.

On the other hand, the individual factors which influence has been investigated most frequently in the reviewed empirical studies include factors upon which participant map skill level depends quite significantly (see Table 3). As is apparent in the case of the tested map skill which was statistically proven to affect map skill level in all eight studies where it was taken into account (Grofelnik \& Pap, 2013; Hanus \& Marada, 2016; Ishikawa, 2016; Michaelidou et al., 2004; Ooms et al., 2015; Postigo \& Pozo, 2004; Umek, 2003; van Dijk et al., 1994).

The difference in influence of identified factors based on map skill type. This finding points not only to the already discussed substantial diversity of individual map skills, but also indirectly to the importance of taking into account the type of map skills which level is investigated when selecting individual factors as independent variables for empirical study. Thanks to visual depiction of the synthesized study results 
(see Figure 5), clusters of influencing factors which seem to be characteristic for level of individual map skill types can be identified.

The factors which are particularly characteristic for maps, such as figure-ground contrast, number of classes in a choropleth map, form of element depiction etc., have only been investigated and proven as significant in the case of ability to read maps (Barker et al., 1986; Gilmartin \& Shelton, 1989; Winn \& Sutherland, 1989).

Only map background complexity has been proven to significantly influence the ability to analyse maps (Michaelidou et al., 2004). It can be said that map analysis especially involves factors which can be generally summarised as being associated with spatial abilities and skills or spatial imagination (general spatial reasoning, previous experience of a spatial task and the method of landform representation) (Hemmer et al., 2013; Ishikawa, 2016; Liben et al., 2013; Malinowski \& Gillespie, 2001; van Dijk et al., 1994).

Factors specific to map drawing also correspond to the characteristics of this type of map skill. Map drawing especially involves factors associated with experience of mapmaking and with the cartographic expertise of the participants in general (field mapping strategy, mapping expertise, map-reasoning level and prior knowledge/understanding of the map concept) (Baker et al., 2012; Gerber, 1984; Harwood \& Usher, 1999; Shin, 2007).

Map drawing tends to be omitted in some theoretical and also empirical works when individual map skill types are distinguished and described (e.g., Kimerling et al., 2009; Liebenberg, 1998; van Dijk et al., 1994; Wiegand, 2006). Presumably, their focus on the use of an already created map is the cause. Moreover, as already mentioned, the reviewed studies identifying map drawing skills frequently substantially differ in methodological approaches chosen. Notwithstanding the difference, a considerable amount of factors has been verified to influence both the map drawing skills and some of the skills related to the map use (e.g., spatial ability, teaching method) as is apparent from Figure 5.

Even factors which according to the reviewed studies significantly influence all four types of map skill can be identified. These include gender, age, grade, expertise in geography, and possession of an atlas (from user characteristics); map type (map characteristics); map skill training, collaborative teaching and the academic major (external factors). Given the generally high number of studies verifying the influence of gender and age, it is no surprise that these factors have stronger links to individual types of map skills (Figure 5). 


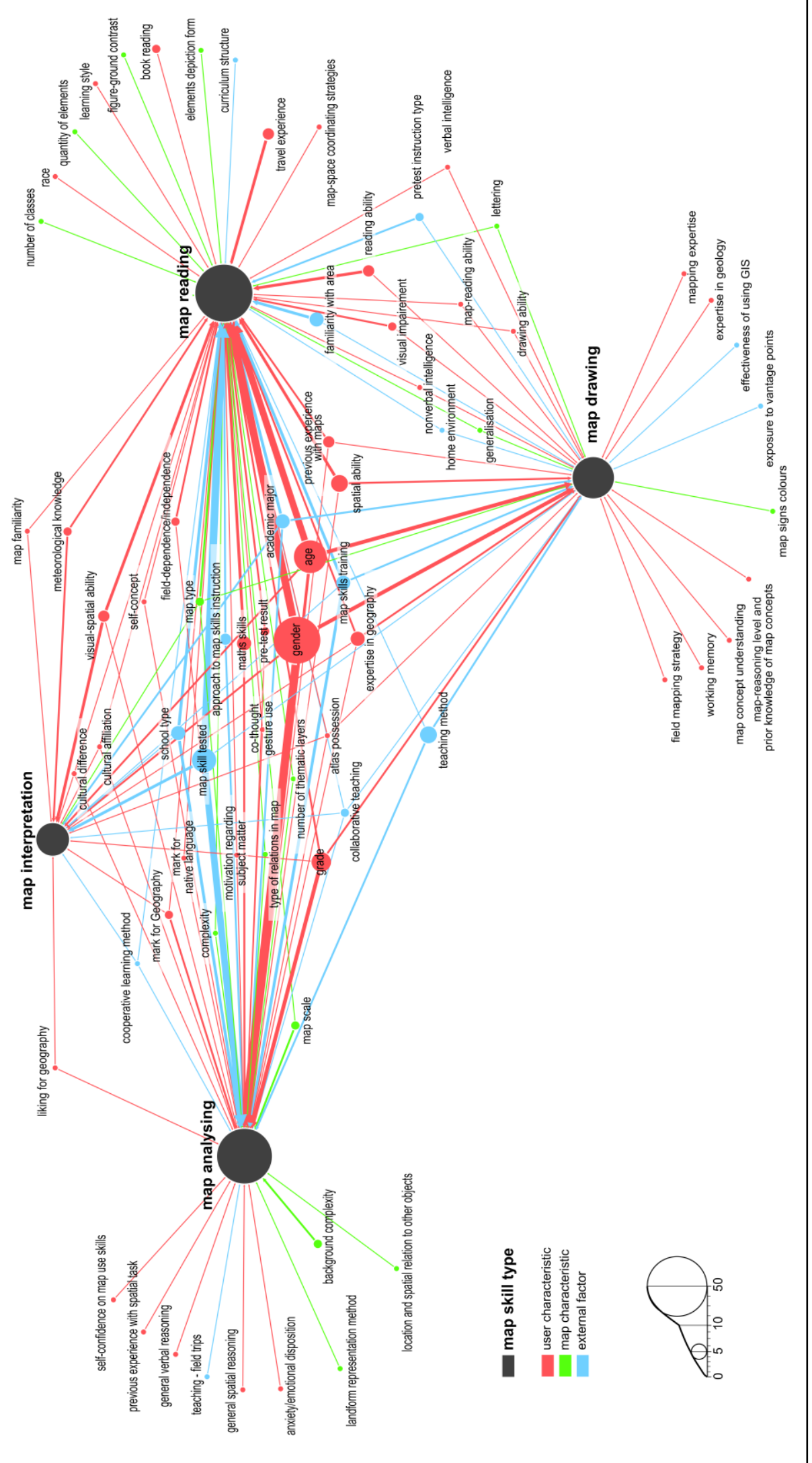

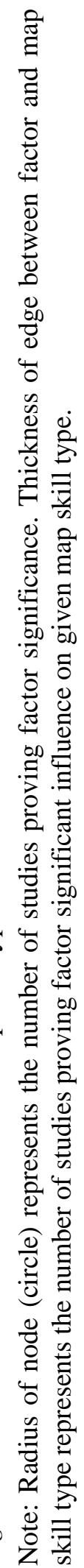




\section{Discussion}

The paper has employed a literature review in order to provide researchers interested in the topic of map skills with a general overview of the current state of knowledge in the field. Specifically, the review has focused on three perspectives, i.e., terminology, methodological approaches, and factors and their effect on map skill level.

The strengths and limitations of this review and its implications for future research are discussed with a focus on gaps in the field of map skill research.

\section{Strengths and Limitations}

The authors are unaware of any other systematic review synthesising empirical studies focusing on map skills. The previous thematically close reviews focused specifically on only one or a few specific aspects of these skills (from the perspective of an independent variable tested or a methodological approach used). Or on the contrary, they pursued more general aim in terms of research topic covered (e.g., Gilmartin \& Patton, 1984; Krassanakis \& Cybulski, 2019; Lauer, Yhang, \& Lourenco, 2019; Zadrozny, McClure, Lee \& Jo, 2016).

Despite the fact that a relatively substantial number of empirical studies has been identified and analysed in this review, it is possible that other suitable studies missed the criteria of the literature search and have therefore not been included. This may be due to the chosen bibliographical databases, the limitation of the review to only peer-reviewed articles written in English or the keywords used during the searches.

As described above, substantial diversity exists in the terms used for the skills which the user employs when using or designing maps. This diversity increased the difficulty of searching for relevant studies. Despite the authors' endeavours to include as keywords all of the terms commonly used for these skills (map skill, map reading, cartographic skill, map interpretation, map understanding, map use skill and mapping skill), subsequent analysis of the discovered studies has shown that this list is far from being exhaustive.

The terminological diversity has probably been caused substantially by the different research focuses of the individual researchers, as map skills are a substantially interdisciplinary topic which is of interest to psychologists, educators, geographers, geographic didactics, cartographers and many other experts. The area of map skills therefore attracts the theoretical (and methodological) starting points of a substantial number of scientific disciplines. Moreover, the map skills research is less or more connected with the even broader research field of spatial abilities, spatial skills and spatial thinking that is not primarily linked to geography as map skills are. As examples of studies focused on these skills from a geography education perspective, see Huynh \& Sharpe (2013), Lee \& Bednarz (2012), and Jo, Hong, \& Verma (2016).

Another aim of this review has been to assist researchers to focus on investigating or, on the other hand, eliminating the influence of significant factors within their selected research design. And moreover, to guide them towards research into those factors which 
influence has yet to be sufficiently investigated, or indeed investigated at all (see below Suggestions for future research).

Unfortunately, it has not been possible to conduct a meta-analysis of the reviewed studies and calculate average effect sizes of individual factors. This is due not only to the distinct heterogeneity of the studies but also to insufficient reports on methodologies and results in a considerable number of studies. In order to provide at least a partial overview of factors investigated, particularly those statistically confirmed as affecting map skills, synthesised conceptual maps were created. These maps clearly depict both the individual factors, their categorisation from the point of view of the main variables entering cartographic communication and the frequency of confirmation of their influence.

The number of factors identified (93) substantially outnumbered the number of studies identified (67) and once more indicated the overall breadth and associated problematic nature of this research topic. Many factors were investigated in only one study and it is therefore probable that the inclusion of a given factor among those which do or do not influence map skills partially depends on the research design selected by the authors. Given this, it is not possible to generalise and it is necessary to become more closely acquainted with each specific study (see the Appendix, where the main outcomes for each study are stated together with the study's basic characteristics).

It is similarly impossible to unambiguously assess factors' influence based merely on the number of studies in which that influence has been proven to be significant. The frequency reflects the "popularity" of the individual factors among authors to a certain extent. It is therefore also important to look at how many studies investigated the factor but did not prove the influence of the factor on map skill level, especially in the case of frequently investigated factors. As such, Figure 4 and Table 3 indicate that, unlike age/grade and map skill tested, which influence is relatively unambiguous, gender (the most frequently investigated factor) is a highly debatable factor (see also Gilmartin \& Patton, 1984; Wiegand, 2006).

Similarly, it is impossible to unequivocally designate which factors must be included in the research design when testing only some or even one specific map skill based on our analysis. This is especially true of skills falling under map interpretation because no empirical study has independently investigated them. Nevertheless, clusters of factors appear in the case of the remaining three types of map skills, despite the connectedness and non-specific nature of some research with regard to the tested types of map skills. These clusters may be at least partially typical for these skill types (see Figure 5) and therefore serve as a guide to researchers when designing future empirical studies.

Despite these limitations, this review provides a number of important findings and conclusions, thanks to which it is possible to propose recommendations for further empirical studies into map skills.

\section{Suggestions for Future Research}

As already stated, the area of map skills is wide-ranging, both in specific skills needed for working with maps and in factors entering into the process of the 
development and/or use of these skills. It is therefore not possible to encompass this topic fully in a single empirical study, let alone identify the level of all specific map skill operations and verify the influence of all potential factors.

Suggestions related to map skills investigated and terms referring to them. This review illustrates a need to use clear terminology and distinguish individual operations with a map based on their cognitive complexity and typology of map skills when planning research. Map work as such can be divided into understanding of map concepts and map skills, which are further divided into four types (of differing cognitive difficulty): reading, analysing, interpreting, and drawing. This proposed typology that is based on both theoretical works and empirical studies should be used to specify the research subject enabling comparability of results.

With respect to the map skill tested, a relatively low number of studies aim to verify level of map interpretation skills (e.g., to critically evaluate a map and to formulate conclusions and predictions based on a map). As such, map skills imposing the least cognitive demands are investigated most frequently (map reading - recognition, understanding and evaluation of symbols and determination of locations) along with those considered important in everyday life (map analysis - way-finding, navigation). Nevertheless, it is the map interpretation that is becoming more and more important in today's world where we are facing a huge amount of (irrelevant and even false) information that can be also depicted on maps of differing cartographic quality. Therefore, research specifically devoted to the students' level of map interpretation skills and factors influencing them is of great importance.

In general, individual studies would be of greater benefit if they focused more closely on specific (types of) map skills or if they at least considered differences in the map skills tested when analysing results and verifying the influence of the factors under investigation. Thereby testing the existence of this dependency separately for different (types of) map skills as factor influence varies by map skill. For the same reason, it is very important for authors to explicitly define the skills investigated or refer to the literature on which the definition concepts are based.

Suggestions related to methodological approaches chosen. Just as it is necessary to theoretically frame the researched map skills and the factors influencing them, so it is essential to report methodologies and results clearly and in detail in order to build a base for future research grounded in previous research designs and findings (similarly Downs (1994) in terms of geography education and National Research Council (2006) in terms of spatial thinking). No matter how much this may seem a matter of course, our analysis has shown many articles fail to meet this standard. In order to lessen the risk of bias in empirical studies and, furthermore, to enable investigation of the same research questions using the same methodologies, but with different participants in different geographical and educational settings, it is necessary for authors to publish their complete research tool in their papers or appendices, provided the publisher and the nature of the research instrument so allow.

Our synthesis also shows that authors have preferred quantitative methods of data collection. Specifically, they make frequent use of tests mostly created by themselves 
comprising multiple-choice questions and maps based on which the questions are answered to identify level of map skills. Map skill research, particularly its international comparability, would be improved by the creation of standardized tests of map skills suitable for use in different national or international contexts (similarly Downs (1994); National Research Council (2006)). The inspiration can be found in recent endeavours to design a standardized test for measuring (geo) spatial thinking (Huynh \& Sharpe, 2013; Lee \& Bednarz, 2012).

Moreover, as Zadrozny, McClure, Lee \& Jo (2016, p. 229) have stated, "collecting and analysing both quantitative and qualitative data proves to be beneficial in improving various aspects of research in the field of geography education" in general. A mixed methodology (e.g., questionnaire with follow-up interviews, map sketching with thinkaloud method, and video recording or eye-tracking experiment with retrospective thinkaloud protocol) would enable researchers to acquire both an overview of the general level of the map skills in the given population and a deeper insight into the topic. Specifically, there is a substantial lack of studies focused on bottlenecks or misconceptions which hamper map skill development, or strategies used when solving tasks with maps or drawing a map. For these research questions, the use of eye-tracking technology that is already substantially popular in cartographic research in general can be of particular benefit (for examples of relevant research see Çöltekin, Fabrikant, \& Lacayo, 2010; Havelková \& Hanus, 2019; Kim, Kim, Shin, \& Ryu, 2015).

Suggestions related to factors tested. A further possibility for the development of knowledge in this research area can involve the abandonment of "traditional" factors such as age and gender. With exception of cases where the influence of these, otherwise most frequently selected, factors has not yet been investigated and researchers intend to study map skills from an as yet insufficiently described point of view. On the basis of this review of individual types of map skills, factors which have been considered in only a small number of studies, but which influence, based on the conclusions of these studies, would appear to be significant, include:

- map reading: familiarity with mapped area, factors describing map design, factors related to teaching - teaching method used in geography education or specifically for map-skill development;

- map analysis: factors characterising spatial ability and imagination, maths skills, factors describing map complexity;

- map interpretation: factors falling under geographical knowledge and skills;

- map drawing: factors related to teaching - teaching method used in geography education or specifically for map-skill development, previous experience with maps and prior cartographic knowledge.

Moreover, it is possible to focus on further studies concerning factors which influence has so far been verified for only some map skills and to verify whether the level of the remaining map skills also depends upon them. Such possibilities based on this review include, for example: 
- map analysis: factors falling under geographical knowledge and skills, familiarity with area;

- map interpretation: previous experience with maps and prior cartographic knowledge, spatial abilities and skills, familiarity with area;

- map drawing: the type of school (e.g., school specialization, type of educational programme), spatial ability, math skills.

It would also be incorrect to assume that all factors which may cause differing levels of map skills have been identified in the studies. Based on theoretical studies, empirical research from related fields and factors identified in this review, the following factors present themselves in this review as ones to which experts in this field should devote their research:

- User characteristics:

- Analytical and statistical reasoning,

- Strategy used for problem-solving,

- Graphicacy,

- Misconceptions in cartography,

- Map characteristics:

○ Comprehensibility/presence of legend,

- Map composition,

- Map cartographic/content accuracy,

- Degree of abstraction of theme/phenomenon/means of expression,

- Orientation of map in relation to cardinal directions,

- The selected cartographic projection,

- External factors:

- Curricular requirements,

- Time limit,

- Teacher's learning and teaching style.

\section{Conclusion}

As the results have shown, level of map skills is affected by a wide range of factors. The majority of factors identified relate to the map user. Moreover, some are also among the most frequently proved to be significant factors (gender, age and grade). Nevertheless, there are also external factors and factors relating to the map characteristics which also have an effect on map skills (e.g., map skill tested, teaching method and map complexity). As map skill tested is one of the key factors, it is not surprising that several factors which seem to be specific to particular map skill types have been identified.

The results of this review could be of benefit not only as an overview of existing research in the map skill field but also as a guide to formulate the research design concept of future studies. The results can be of particular assistance when designating research goals. Specifically, they can be helpful in selection of map skills to be tested, i.e., with regard to awareness of cognitive and content differences between individual map operations. And moreover, in selection of factors to be investigated as independent variables explaining differences in map skill levels. Furthermore, the review of the used 
methodological approaches can be an inspirational resource for experts when selecting and creating their own research instruments.

Besides its benefits for researchers devoted to the issue of map skills, this review can be of use to journal editors. Eligible reviewers for newly submitted manuscripts aiming to investigate map skills can be found among the authors of reviewed studies. Moreover, the editors can efficiently check if the authors of the manuscript are well acquainted with the current state of art. And, specifically, if their study builds upon the results of the previous ones and focuses on yet to be sufficiently investigated perspectives. Besides that, the recommendations of this study related to the methodological approaches, research design, and research tools are of use for journal editors during evaluation of manuscript innovativeness and merits from the methodological point of view.

Even for the (geography) teachers, the results of the review can be beneficial as they indirectly provide several suggestions. The one of the most important is to incorporate in lessons activities comprising of use and design of maps that are diverse in every perspective (e.g., map type used, map skill developed, geography topic taught, etc.). This variety can enable any student to discover pleasure in working with maps. The teachers should as well be cautious of factors that can unnecessarily impede students' use of maps (e.g., lack of required math skills, high map complexity, and unfamiliarity with the depicted area). Additionally, knowledge of factors that can influence the process of map skill development or can have different impact on each student (i.e., resulting in different level of map skill among students in one class or school), can be critical and helpful in increasing the effectivity of teaching and in achieving the educational goals.

Finally, in concordance with the suggestions for researchers, teachers should devote more attention to developing map skills that are essential in today's world. Therefore, to cognitively demanding skills (map interpretation) besides others, e.g., critical evaluation of information depicted on a map, formulation of generalizations, conclusions, and predictions based on map(s).

\section{References}

Aksoy, B. (2013). Investigation of mapping skills of pre-service teachers as regards to various parameters. Educational Research and Reviews, 8(4), 134-143.

Alhosani, N. M. D., \& Yagoub, M. M. (2015). Geographic skills: a case study of students in the United Arab Emirates. International Research in Geographical and Environmental Education, 24(1), 95-102.

Allen, G. L., Miller Cowan, C. R., \& Power, H. (2006). Acquiring information from simple weather maps: Influences of domain-specific knowledge and general visual-spatial abilities. Learning and Individual Differences, 16(4), 337-349.

Baker, K. M., Petcovic, H., Wisniewska, M., \& Libarkin, J. C. (2012). Spatial signatures of mapping expertise among field geologists. Cartography and Geographic Information Science, 39(3), 119-132. 
Havelková, L., Hanus, M. (2019)/ Map Skills in Education: A Systematic Review of Terminology...

Barker, P., Hailstone, M., \& Simmonds, M. (1986). An experimental study of some effects of figure-ground contrast on the use of street maps. Information Design Journal, 4(3), 212220 .

Battersby, S. E., Golledge, R. G., \& Marsh, M. J. (2006). Incidental learning of geospatial concepts across grade levels: map overlay. Journal of Geography, 105(4), 139-146.

Bausmith, J. M., \& Leinhardt, G. (1998). Middle-school students' map construction: understanding complex spatial displays. Journal of Geography, 97(3), 93-107.

Beatty, W. W., \& Tröster, A. I. (1987). Gender differences in geographical knowledge. Sex Roles, 16(11-12), 565-590.

Bein, F. L. (1990). Baseline geography competency test: administered in Indiana universities. Journal of Geography, 89(6), 260-265.

Bein, F. L., Hayes, J. J., \& Jones, T. G. (2009). Fifteen year follow-up geography skills test administered in Indiana, 1987 and 2002. Journal of Geography, 108(1), 30-36.

Blades, M., Blaut, J. M., Darvizeh, Z., Elguea, S., Sowden, S., Soni, D., ... Uttal, D. (1998). A cross-cultural study of young children's mapping abilities. Transactions of the Institute of British Geographers, 23(2), 269-277.

Board, C. (1978). Map reading tasks appropriate in experimental studies in cartographic communication. Cartographica: The International Journal for Geographic Information and Geovisualization, 15(1), 1-12.

Board, C. (1984). Higher order map-using tasks: geographical lessons in danger of being forgotten. Cartographica: The International Journal for Geographic Information and Geovisualization, 21(1), 85-97.

Carter, J. R. (2005). The many dimensions of map use. Proceedings of the XXII International Cartographic Conference, (A Coruña), 1-9.

Catling, S. J. (2005). Developing children's understanding and use of maps. In C. Lee \& C. C. Hung (Eds.), Primary Social Studies: Exploring Pedagogy and Content (pp. 220- 250). Singapore: Marshall Cavendish Education.

Chang, K. T., \& Antes, J. R. (1987). Sex and cultural differences in map reading. American Cartographer, 14(1), 29-42.

Clark, D., Reynolds, S., Lemanowski, V., Stiles, T., Yasar, S., Proctor, S., .. Corkins, J. (2008). University students' conceptualization and interpretation of topographic maps. International Journal of Science Education, 30(3), 377-408.

Çöltekin, A., Fabrikant, S. I., \& Lacayo, M. (2010). Exploring the efficiency of users' visual analytics strategies based on sequence analysis of eye movement recordings. International Journal of Geographical Information Science, 24(10), 1559-1575.

DiBiase, D., Corbin, T., Fox, T., Francica, J., Green, K., Jackson, J., .. Van Sickle, J. (2010). The new geospatial technology competency model: bringing workforce needs into focus. Journal of the Urban \& Regional Information Systems Association, 22(2), 55-72.

Downs, R. M. (1994). The need for research in geography education: it would be nice to have some data. Journal of Geography, 93(1), 57-60.

Drumheller, S. J. (1968). Conjure up a map - A crucial but much neglected skill. Journal of Geography, 67(3), 140-146. 
Eve, R. A., Price, B., \& Counts, M. (1994). Geographic illiteracy among college students. Youth \& Society, 25(3), 408-427.

Fox, P., \& Avramidis, E. (2003). An evaluation of an outdoor education programme for students with emotional and behavioural difficulties. Emotional and Behavioural Difficulties, 8(4), 267-283.

Gerber, R. (1984). Factors affecting the competence and performance in map language for children at the concrete level of map-reasoning. Cartography, 13(3), 205-213.

Gilmartin, P. P., \& Patton, J. C. (1984). Comparing the sexes on spatial abilities: map-use skills. Annals of the Association of American Geographers, 74(4), 605-619.

Gilmartin, P. P., \& Shelton, E. (1989). Choropleth maps on high resolution CRTs, the effects of number of classes and hue on communication. Cartographica, 26(2), 40-52.

Gökçe, N. (2015). Social studies in improving students' map skills: teachers' opinions. Educational Sciences: Theory and Practice, 15(5), 1345-1362.

Griffin, M. M. (1995). You can't get there from here: situated learning transfer, and map skills. Contemporary Educational Psychology, 20(1), 65-87.

Griffin, M. M., \& Griffin, B. W. (1996). Situated cognition and cognitive style: effects on students' learning as measured by conventional tests and performance assessments. The Journal of Experimental Education, 64(4), 293-308.

Grofelnik, H., \& Pap, I. (2013). Mastery of long-term cartographic knowledge and skills of new entry secondary level pupils. Kartografija $i$ Geoinformacije (Cartography and Geoinformation), 12(19), 86-102.

Hamerlinck, J. D. (2015). Whither goes the "maps" course? Maintaining map-use concepts, skills, and appreciation in GIS\&T curricula. Cartography and Geographic Information Science, 42(1), 11-17.

Hanus, M., \& Havelková, L. (2019). Teachers' concepts of map skill development. Journal of Geography, 118(3), 101-116.

Hanus, M., \& Marada, M. (2014). Mapové dovednosti: vymezení a výzkum. Geografie, 119(4), 406-422.

Hanus, M., \& Marada, M. (2016). What does a map-skills-test tell us about Czech pupils? Geografie, 121(2), 279-299.

Harte, J., \& Dunbar, C. (1994). Skills in Geography. Cambridge: Cambridge University Press.

Harwood, D., \& Usher, M. (1999). Assessing progression in primary children's map drawing skills. International Research in Geographical and Environmental Education, 8(3), 222238.

Havelková, L., \& Hanus, M. (2019). Research into map-analysis strategies: theory- and datadriven approaches. Geografie, 124(2), 187-216.

Hemmer, I., Hemmer, M., Kruschel, K., Neidhardt, E., Obermaier, G., \& Uphues, R. (2013). Which children can find a way through a strange town using a streetmap? - results of an empirical study on children's orientation competence. International Research in Geographical and Environmental Education, 22(1), 23-40.

Henrie, R. L., Aron, R. H., Nelson, B. D., \& Poole, D. A. (1997). Gender-related knowledge variations within geography. Sex Roles, 36(9), 605-623. 
Herrmann, D., \& Pickle, L. W. (1996). A cognitive subtask model of statistical map reading. Visual Cognition, 3(2), 165-190.

Higgins, J. P. T., \& Green, S. (2011). Cochrane handbook for systematic reviews of interventions. Hoboken, N.J.: Wiley.

Hirsch, P. L., \& Sandberg, E. H. (2013). Development of map construction skills in childhood. Journal of Cognition and Development, 14(3), 397-423.

Hurst, P., \& Clough, P. (2013). Will we be lost without paper maps in the digital age? Journal of Information Science, 39(1), 48-60.

Huynh, N. T., \& Sharpe, B. (2013). An Assessment Instrument to Measure Geospatial Thinking Expertise. Journal of Geography, 112(1), 3-17.

Ishikawa, T. (2016). Spatial thinking in geographic information science: Students' geospatial conceptions, map-based reasoning, and spatial visualization ability. Annals of the American Association of Geographers, 106(1), 76-95.

Jo, I., Hong, J. E., \& Verma, K. (2016). Facilitating spatial thinking in world geography using web-based GIS. Journal of Geography in Higher Education, 40(3), 442-459

Johnson, D. W., Johnson, R. T., Stanne, M. B., \& Garibaldi, A. (1990). Impact of group processing on achievement in cooperative groups. The Journal of Social Psychology, $130(4), 507-516$.

Kastens, K. A., \& Liben, L. S. (2010). Children's strategies and difficulties while using a map to record locations in an outdoor environment. International Research in Geographical and Environmental Education, 19(4), 315-340.

Keates, J. S. (1996). Understanding maps. Harlow: Longman.

Kelly, J. T., Kelly, G. N., \& Miller, R. B. (1987). Logo experience: Effects on map skills. Computers in the Schools, 4(2), 57-64.

Kim, K., Kim, M., Shin, J., \& Ryu, J. (2015). Eye-movement analysis of students' active examination strategy and its transfer in visuospatial representations. Journal of Geography, 114(4), 133-145.

Kimerling, A. J., Buckley, A. R., Muehrcke, P. C., \& Muehrcke, J. O. (2009). Map Use: Reading and Analysis. Redlands: ESRI Press Academic.

Koláčný, A. (1969). Cartographic information - a fundamental concept and term in modern cartography. The Cartographic Journal, 6(1), 47-49.

Krassanakis, V., \& Cybulski, P. (2019). A review on eye movement analysis in map reading process: The status of the last decade. Geodesy and Cartography, 68(1), 191-209.

LaSpina, J. A. (1998). The visual turn and the transformation of the textbook. Mahwah, NJ: Routledge.

Lauer, J. E., Yhang, E., \& Lourenco, S. F. (2019). The development of gender differences in spatial reasoning: A meta-analytic review. Psychological Bulletin, 145(6), 537-565.

Lee, J., \& Bednarz, R. (2012). Components of spatial thinking: evidence from a spatial thinking ability test. Journal of Geography, 111(1), 15-26.

Leinhardt, G., Stainton, C., \& Bausmith, J. M. (1998). Constructing maps collaboratively. Journal of Geography, 97(1), 19-30. 
Liben, L. S., \& Yekel, C. A. (1996). Preschoolers' understanding of plan and oblique maps: the role of geometric and representational correspondence. Child Development, 67(6), 27802796.

Liben, L. S., Myers, L. J., Christensen, A. E., \& Bower, C. A. (2013). Environmental-scale map use in middle childhood: links to spatial skills, strategies, and gender. Child Development, 84(6), 2047-2063.

Liebenberg, E. C. (1998). Teaching map use in a multicultural environment. South African Geographical Journal, 80(2), 111-117.

Lim, K. Y. T. (2005). Augmenting spatial intelligence in the geography classroom. International Research in Geographical and Environmental Education, 14(3), 187-199.

Livni, S., \& Bar, V. (2001). A controlled experiment in teaching physical map skills to grade 4 pupils in elementary schools. International Research in Geographical and Environmental Education, 10(2), 149-167.

Logan, T., Lowrie, T., \& Diezmann, C. M. (2014). Co-thought gestures: supporting students to successfully navigate map tasks. Educational Studies in Mathematics, 87(1), 87-102.

Malinowski, J. C., \& Gillespie, W. T. (2001). Individual differences in performance on a largescale, real-world wayfinding task. Journal of Environmental Psychology, 21(1), 73-82.

Matthews, M. H. (1986). Gender, graphicacy and geography. Educational Review, 38(3), 259271.

McClure, R. W. (1992). A conceptual model for map skills curriculum development based upon a cognitive field theory philosophy (Unpublished $\mathrm{PhD}$ Dissertation). Oklahoma State University, Oklahoma.

McKissick, B. R., Spooner, F., Wood, C. L., \& Diegelmann, K. M. (2013). Effects of computerassisted explicit instruction on map-reading skills for students with autism. Research in Autism Spectrum Disorders, 7(12), 1653-1662.

Michaelidou, E., Nakos, B., \& Filippakopoulou, V. (2004). The ability of elementary school children to analyse general reference and thematic maps. Cartographica: The International Journal for Geographic Information and Geovisualization, 39(4), 65-88.

Moher, D., Liberati, A., Tetzlaff, J., Altman, D. G., \& The PRISMA Group. (2009). Preferred reporting items for systematic reviews and meta-analyses: The PRISMA statement. PLOS Medicine, 6(7), 1-28.

National Research Council. (2006). Learning to Think Spatially. Retrieved from http://www.nap.edu/catalog/11019

Nelson, B. D., Henrie, R. L., Aron, R. H., \& Poole, D. A. (1996). Academic achievement variations in geography: A public-parochial comparison. Great Lakes Geographer, 3(2), $51-56$.

Ooms, K., De Maeyer, P., Dupont, L., Van der Veken, N., Van de Weghe, N., \& Verplaetse, S. (2015). Education in cartography: what is the status of young people's map-reading skills? Cartography and Geographic Information Science, 43(2), 134-153.

Pedersen, P., Farrell, P., \& McPhee, E. (2005). Paper versus Pixel: effectiveness of paper versus electronic maps to teach map reading skills in an introductory physical geography course. Journal of Geography, 104(5), 195-202. 
Pike, E., Blades, M., \& Spencer, C. (1992). a comparison of two types of tactile maps for blind children. Cartographica, 29(3-4), 83-88.

Postigo, Y., \& Pozo, J. I. (1998). The learning of a geographical map by experts and novices. Educational Psychology, 18(1), 65-80.

Postigo, Y., \& Pozo, J. I. (2004). On the road to graphicacy: The learning of graphical representation systems. Educational Psychology, 24(5), 623-644.

Riding, R. J., \& Boardman, D. J. (1983). The relationship between sex and learning style and graphicacy in 14- year- old children. Educational Review, 35(1), 69-79.

Rittschof, K. A., Griffin, M. M., \& Custer, W. L. (1998). Learner differences affecting schemata for thematic maps. International Journal of Instructional Media, 25(2), 179-199.

Robinson, A. H. (1995). Elements of Cartography. New York: Wiley.

Roth, R. E. (2012). cartographic interaction primitives: framework and synthesis. The Cartographic Journal, 49(4), 376-395.

Scevak, J. J., \& Moore, P. J. (1998). Levels of processing effects on learning from texts with maps. Educational Psychology, 18(2), 133-155.

Schlemper, M. B., Adams, J. K., \& Solem, M. (2014). Geographers in business, government, and nonprofit organizations: skills, challenges, and professional identities. The Professional Geographer, 66(3), 480-492.

Schulze, U., Kanwischer, D., \& Reudenbach, C. (2011). Competence dimensions in a Bolognaoriented GIS education. In T. Jekel, A. Koller, AGIT-Symposium, \& Geoinformatics Forum (Eds.), Learning with GI 2011. Berlin: Wichmann.

Shin, E. K. (2007). Using geographic information system (GIS) technology to enhance elementary students' geographic understanding. Theory \& Research in Social Education, $35(2), 231-255$.

Sholl, M. J., \& Egeth, H. E. (1982). Cognitive correlates of map-reading ability. Intelligence, 6(2), 215-230.

Solem, M. (2017). Geography education, workforce trends, twenty-first-century skills, and geographical capabilities. In D. Richardson, N. Castree, M. F. Goodchild, A. Kobayashi, W. Liu, \& R. A. Marston (Eds.), The International Encyclopedia of Geography (pp. 1-9).

Solem, M., Cheung, I., \& Schlemper, M. B. (2008). Skills in professional geography: an assessment of workforce needs and expectations. The Professional Geographer, 60(3), $356-373$.

Sowden, S., Stea, D., Blades, M., Spencer, C., \& Blaut, J. M. (1996). Mapping abilities of fouryear-old children in York, England. Journal of Geography, 95(3), 107-111.

Teck, L. B. (1989). Effects of practical experience and sequential skills in map reading. Singapore Journal of Education, 10(1), 55-59.

Trifonoff, K. M. (1995). Going beyond location: Thematic maps in the early elementary grades. Journal of Geography, 94(2), 368-374.

Ugodulunwa, C., \& Wakjissa, S. (2015). Use of Portfolio Assessment Technique in Teaching Map Sketching and Location in Secondary School Geography in Jos, Nigeria. Journal of Education and Practice, 6(17), 23-30. 
Umek, M. (2003). A comparison of the effectiveness of drawing maps and reading maps in beginning map teaching. International Research in Geographical and Environmental Education, 12(1), 18-31.

Ungar, S., Blades, M., \& Spencer, C. (1997). Strategies for knowledge acquisition from cartographic maps by blind and visually impaired adults. Cartographic Journal, 34(2), 93-110.

van der Schee, J. A., \& van Dijk, H. (1999). The effect of student freedom of choice in learning map skills. International Research in Geographical and Environmental Education, 8(3), 256-267.

van Dijk, H., van der Schee, J., Trimp, H., \& van der Zijpp, T. (1994). Map skills and geographical knowledge. International Research in Geographical and Environmental Education, 3(1), 68-80.

Wiegand, P. (2006). Learning and Teaching with Maps. New York: Routledge.

Wiegand, P., \& Stiell, B. (1997). children's relief maps of model landscapes. British Educational Research Journal, 23(2), 179-192.

Winn, W. D., \& Sutherland, S. W. (1989). Factors influencing the recall of elements in maps and diagrams and the strategies used to encode them. Journal of Educational Psychology, 81(1), 33-39.

Wood, M. (1972). Human factors in cartographic communication. The Cartographic Journal, 9(2), 123-132.

Zadrozny, J., McClure, C., Lee, J., \& Jo, I. (2016). Designs, Techniques, and Reporting Strategies in Geography Education: A Review of Research Methods. Review of International Geographical Education Online, 6(3), 216-233.

\section{Acknowledgement}

Funding for this research was provided by the Charles University Grant Agency, Project 42217, "Students' Strategies for Solving Tasks with Maps"; and by Charles University Research Centre program no. UNCE/HUM/024.

\section{Bibliographical Statements}

Lenka HAVELKovÁ is a PhD candidate at the Centre for Geographical and Environmental Education, Department of Social Geography and Regional Development, Faculty of Science, Charles University, Prague. Her research focuses on educational cartography and map skills. Since starting her PhD project, she has specifically developed a research interest in students' strategies for solving problem tasks with maps and students' misconceptions influencing the understanding and use of maps.

Martin HANUS is an assistant professor at the Centre for Geographical and Environmental Education, Department of Social Geography and Regional Development, Faculty of Science, Charles University, Prague. His research activities focus mainly on map skills and related aspects of geography education (including curriculum, teaching, strategies, and educational outcomes). Moreover, he is interested in research in geography education in general, such as world-mindedness of young people, geography skills, geocapabilities, and geographical disparities. 


\section{Appendix $\mathbf{I}$.}

Main characteristics and outcomes of reviewed studies.

Note: Only the research instruments used for map skill testing are stated. The explanation of used abbreviations: $\mathrm{N}$ - size of research sample, $\mathrm{U}$ - university students (i.e., approx. 18 years and older), CO - correlational study, EI - study with experimental design including intervention, $\mathrm{E}$ - study with experimental design (intervention not included), $\mathrm{C}$ - confirmed independent variable, $\mathrm{NC}$ - non-confirmed independent variable, $\mathrm{C} \& \mathrm{NC}$ - partially confirmed independent variable.

\begin{tabular}{|c|c|c|c|c|c|}
\hline 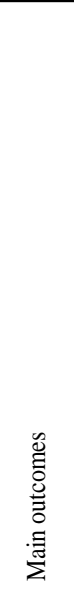 & 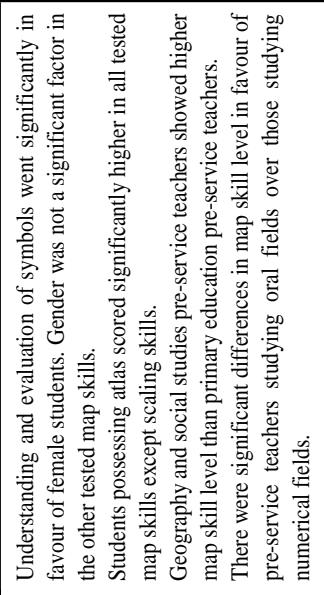 & 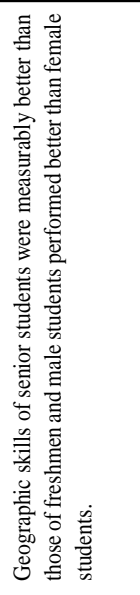 & 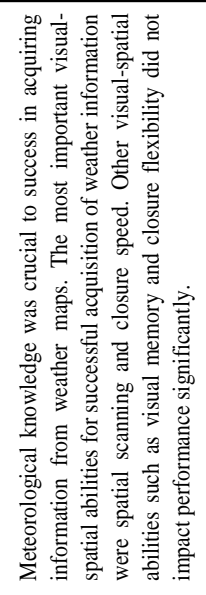 & 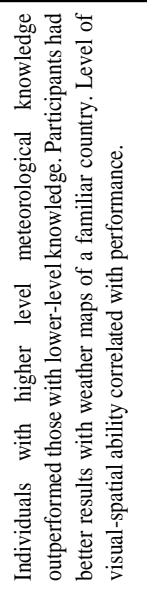 & 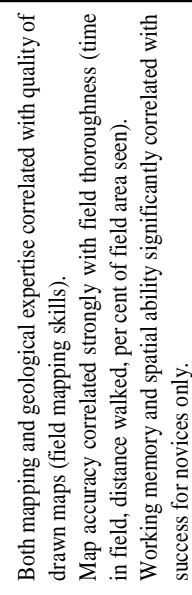 \\
\hline 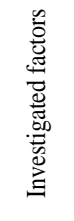 & 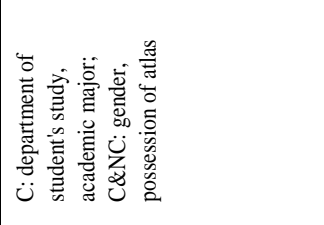 & 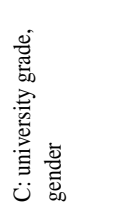 & 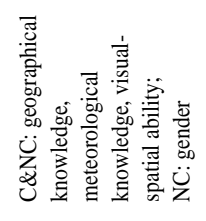 & 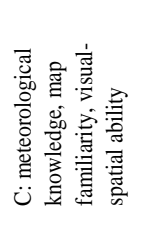 & 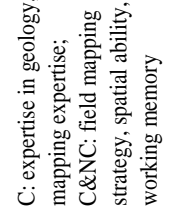 \\
\hline 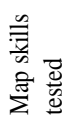 & 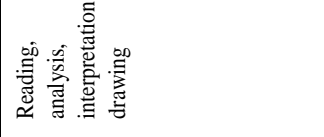 & 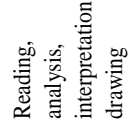 & 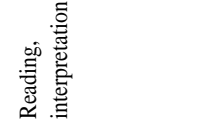 & 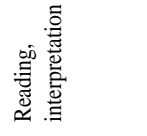 & 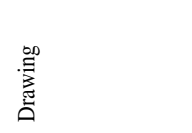 \\
\hline 涉 & 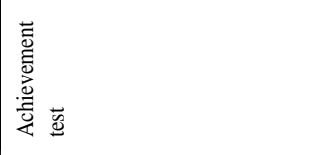 & 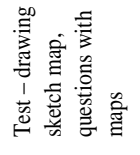 & 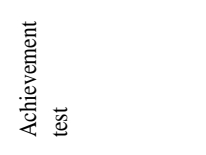 & 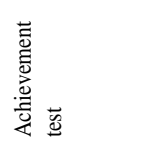 & 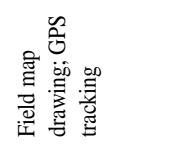 \\
\hline 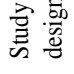 & 8 & 8 & 8 & 8 & 8 \\
\hline$\underset{8}{8}$ & D & D & D & D & D \\
\hline z & g & 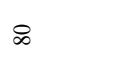 & D) & $\bar{\sigma}$ & 5 \\
\hline 音 & 离 & 晟 & 艿 & 苑 & 要 \\
\hline 荵 & 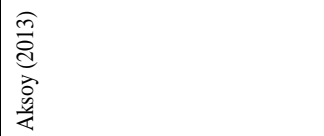 & 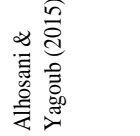 & 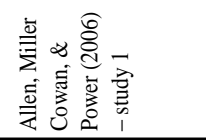 & 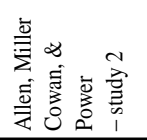 & 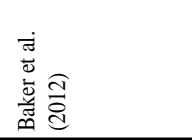 \\
\hline
\end{tabular}




\begin{tabular}{|c|c|c|c|c|c|c|}
\hline 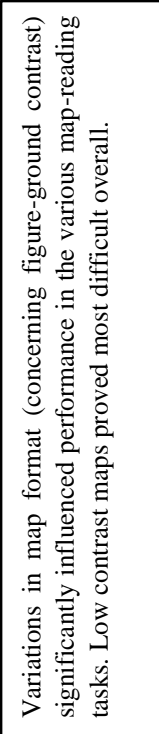 & 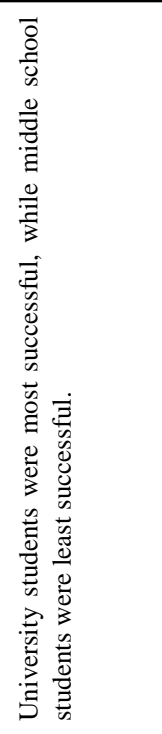 & 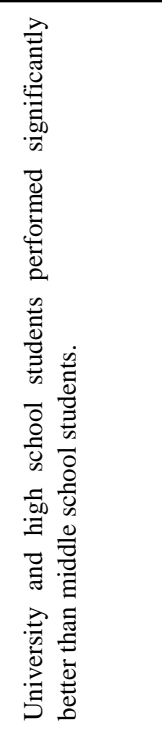 & 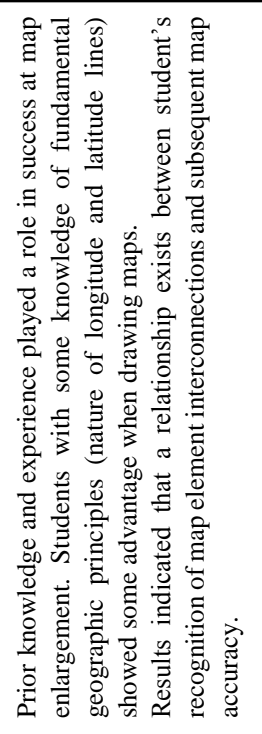 & 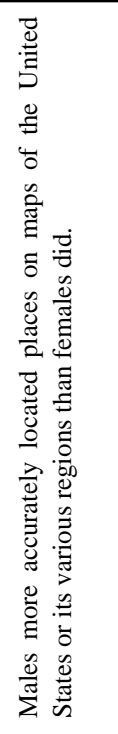 & 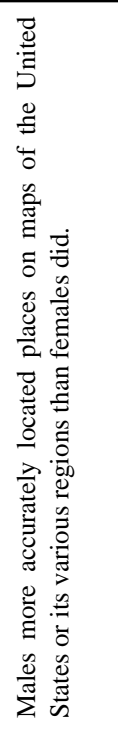 & 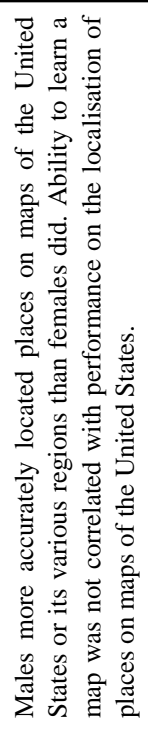 \\
\hline 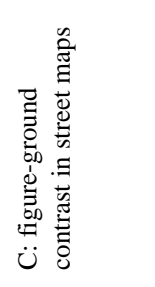 & 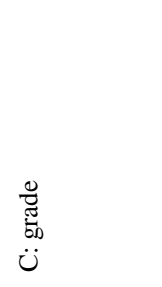 & 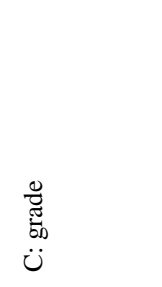 & 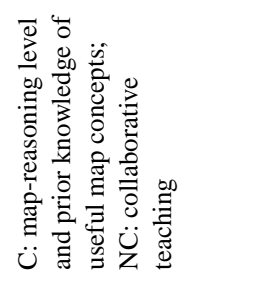 & 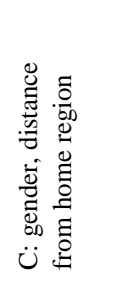 & 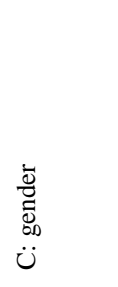 & 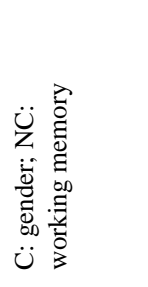 \\
\hline 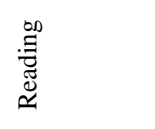 & 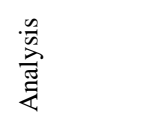 & $\begin{array}{l}\frac{n}{0} \\
\frac{0}{0} \\
\frac{\pi}{4}\end{array}$ & 惡 & 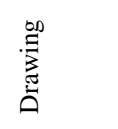 & 忥 & : \\
\hline 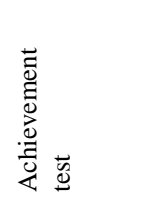 & 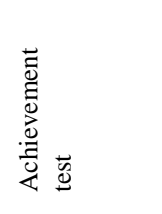 & 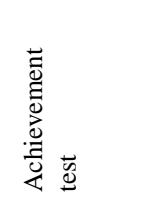 & 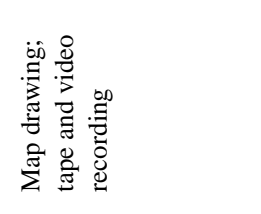 & 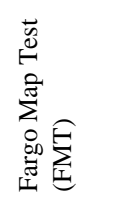 & 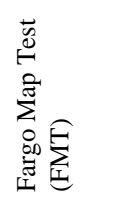 & 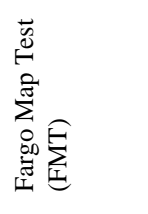 \\
\hline w & 8 & 8 & 山 & ○ & 8 & 8 \\
\hline$\supset$ & $\stackrel{\substack{\infty \\
I}}{=}$ & $\stackrel{\substack{\infty \\
I}}{=}$ & $\frac{ \pm}{d}$ & D & D & D. \\
\hline 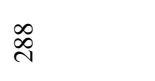 & $\stackrel{\infty}{I}$ & $\stackrel{\&}{\circ}$ & $\simeq$ & $\stackrel{\check{\beth}}{\cong}$ & $n$ & $\stackrel{\infty}{\beth}$ \\
\hline 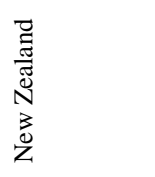 & 峁 & $\overleftrightarrow{\Delta}$ & $\begin{array}{l}\overleftrightarrow{2} \\
0\end{array}$ & $\begin{array}{l}\overleftrightarrow{n} \\
\tilde{n}\end{array}$ & 苑 & 芯 \\
\hline 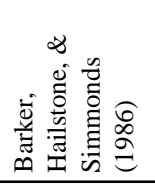 & 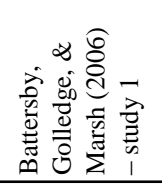 & 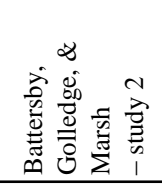 & 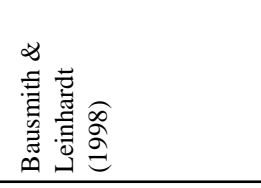 & 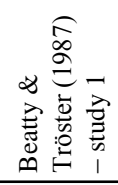 & 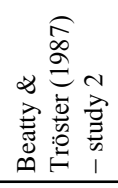 & 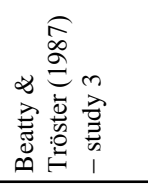 \\
\hline
\end{tabular}




\begin{tabular}{|c|c|c|c|c|c|}
\hline 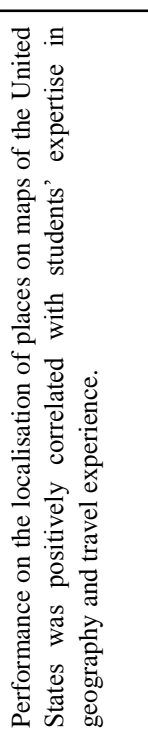 & 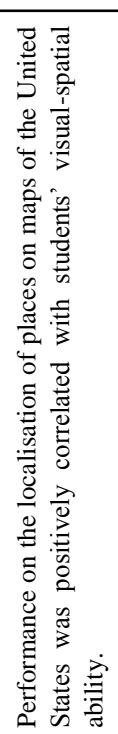 & 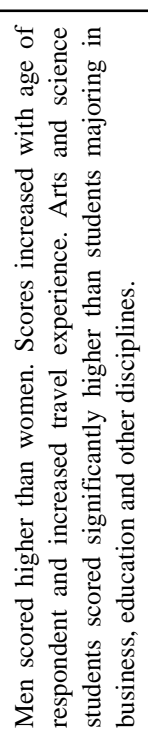 & 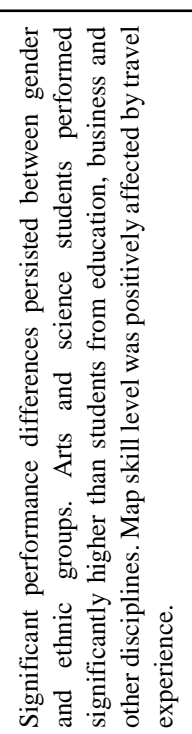 & 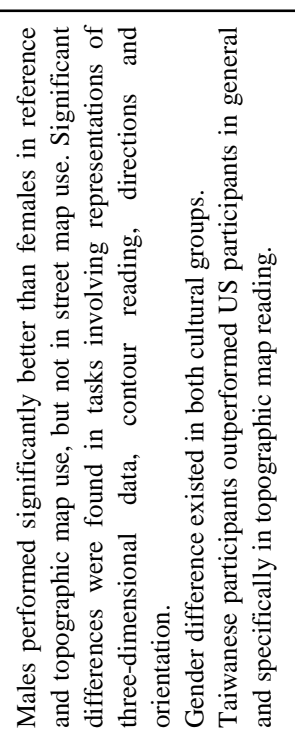 & 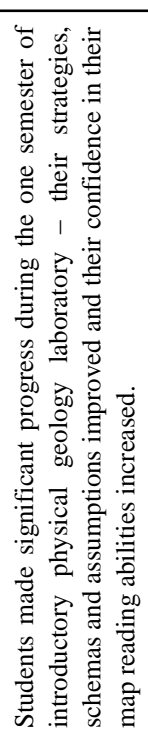 \\
\hline 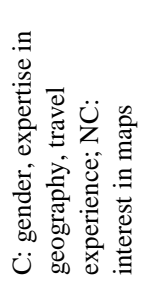 & 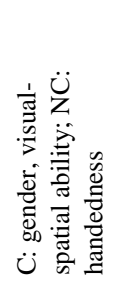 & 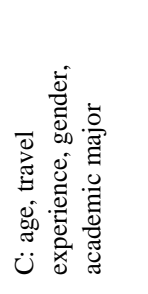 & 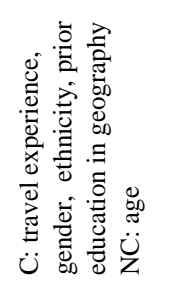 & 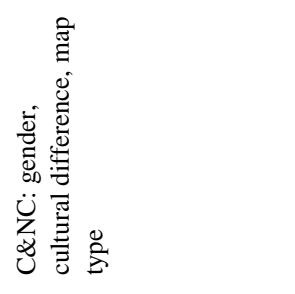 & 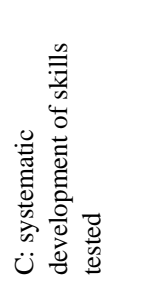 \\
\hline 号 & 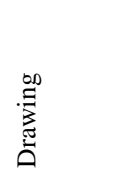 & 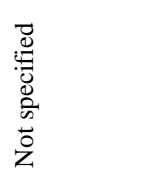 & 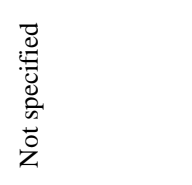 & 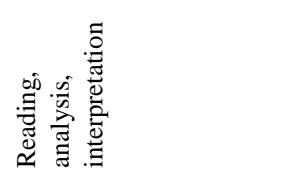 & 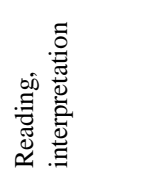 \\
\hline 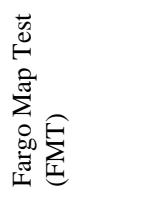 & 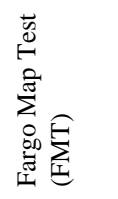 & 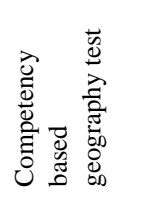 & 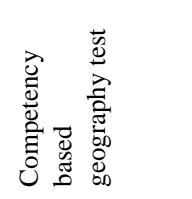 & 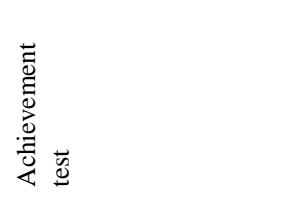 & 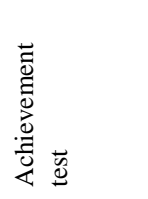 \\
\hline 8 & 8 & 8 & 8 & $\omega$ & 可 \\
\hline D & D. & $D$ & $\supset$ & $\supset$ & 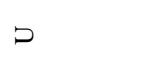 \\
\hline$\stackrel{d}{g}$ & in & $\begin{array}{l}\tilde{\infty} \\
\tilde{ల}\end{array}$ & 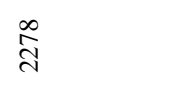 & ठิ & $\stackrel{\infty}{=}$ \\
\hline $\begin{array}{l}\mathbb{b} \\
\tilde{b}\end{array}$ & $\begin{array}{l}\mathbb{s} \\
\tilde{n}\end{array}$ & $\begin{array}{l}\overleftrightarrow{4} \\
\tilde{n}\end{array}$ & $\begin{array}{l}\mathbb{3} \\
0 \\
0\end{array}$ & 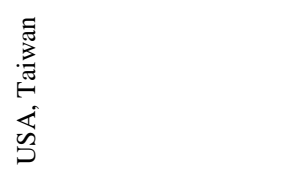 & 范 \\
\hline 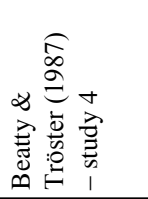 & 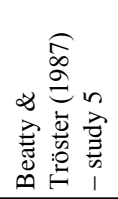 & 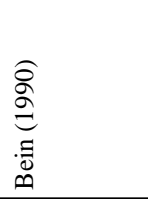 & 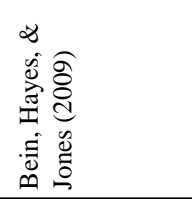 & 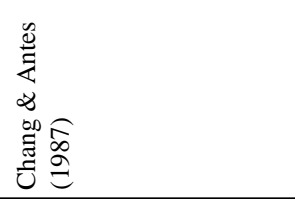 & 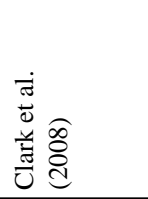 \\
\hline
\end{tabular}




\begin{tabular}{|c|c|c|c|}
\hline 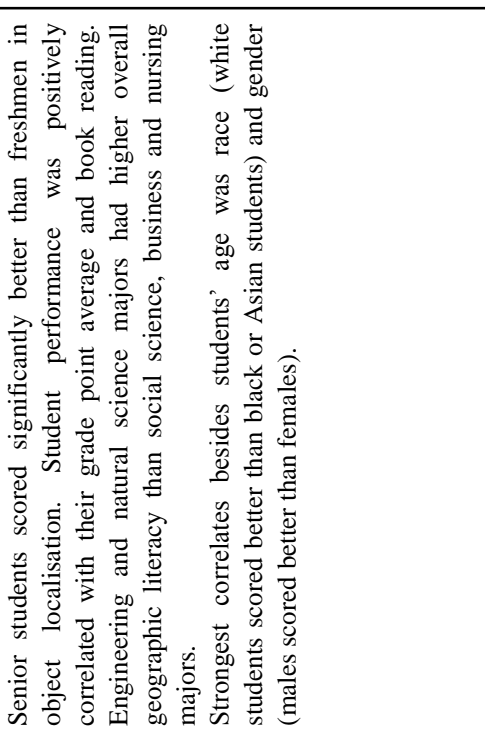 & 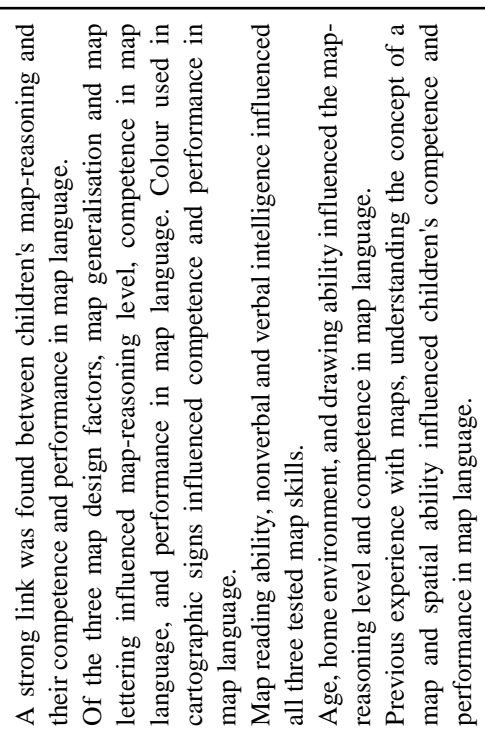 & 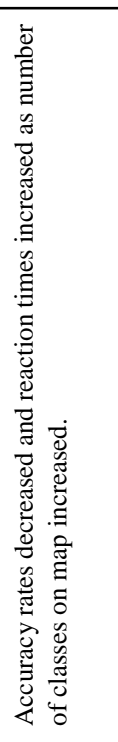 & 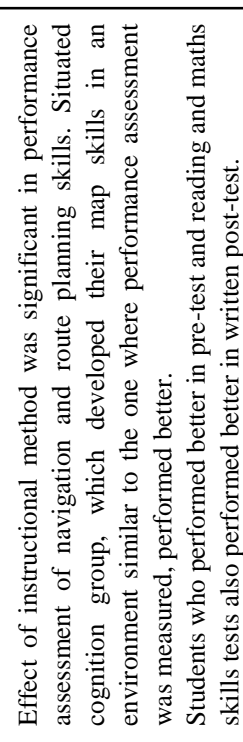 \\
\hline 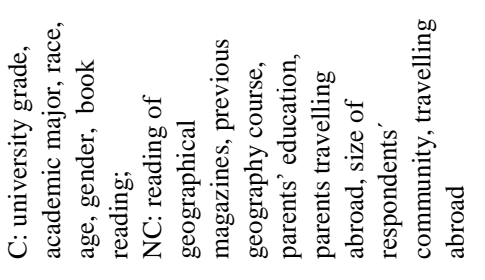 & 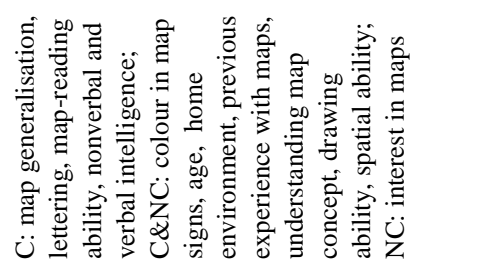 & 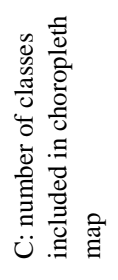 & 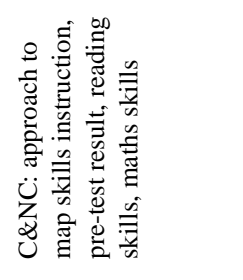 \\
\hline 先 & 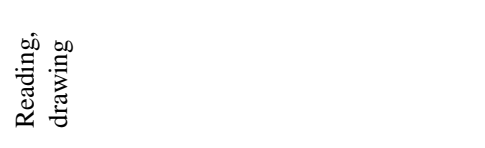 & 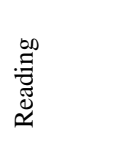 & 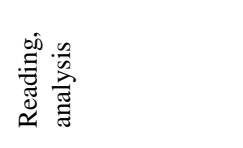 \\
\hline 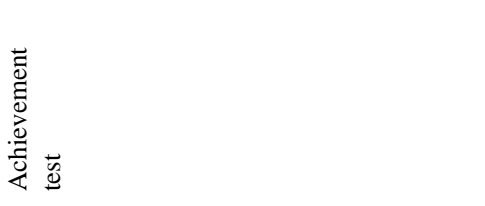 & 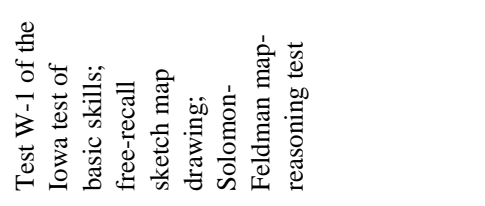 & 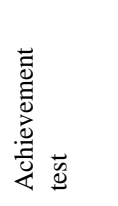 & 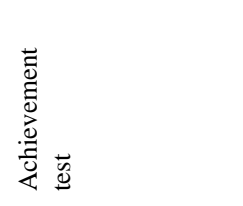 \\
\hline o & 8 & w & $\vec{\Psi}$ \\
\hline & $\underset{\infty}{t}$ & D & $\frac{0}{a}$ \\
\hline$m$ & fo & q & gे \\
\hline 8 & 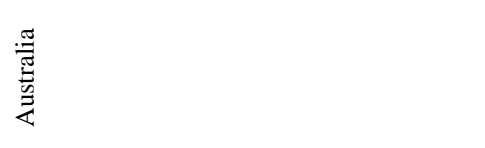 & & $\overleftrightarrow{\Delta}$ \\
\hline 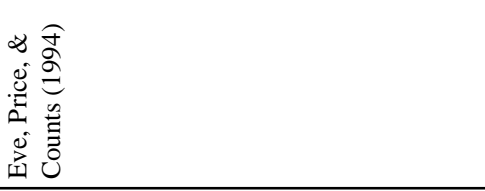 & 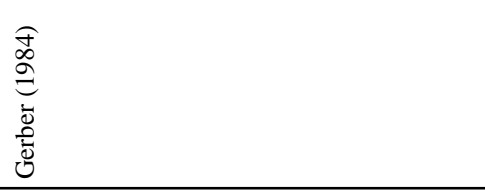 & 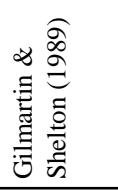 & 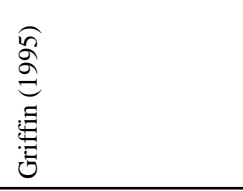 \\
\hline
\end{tabular}




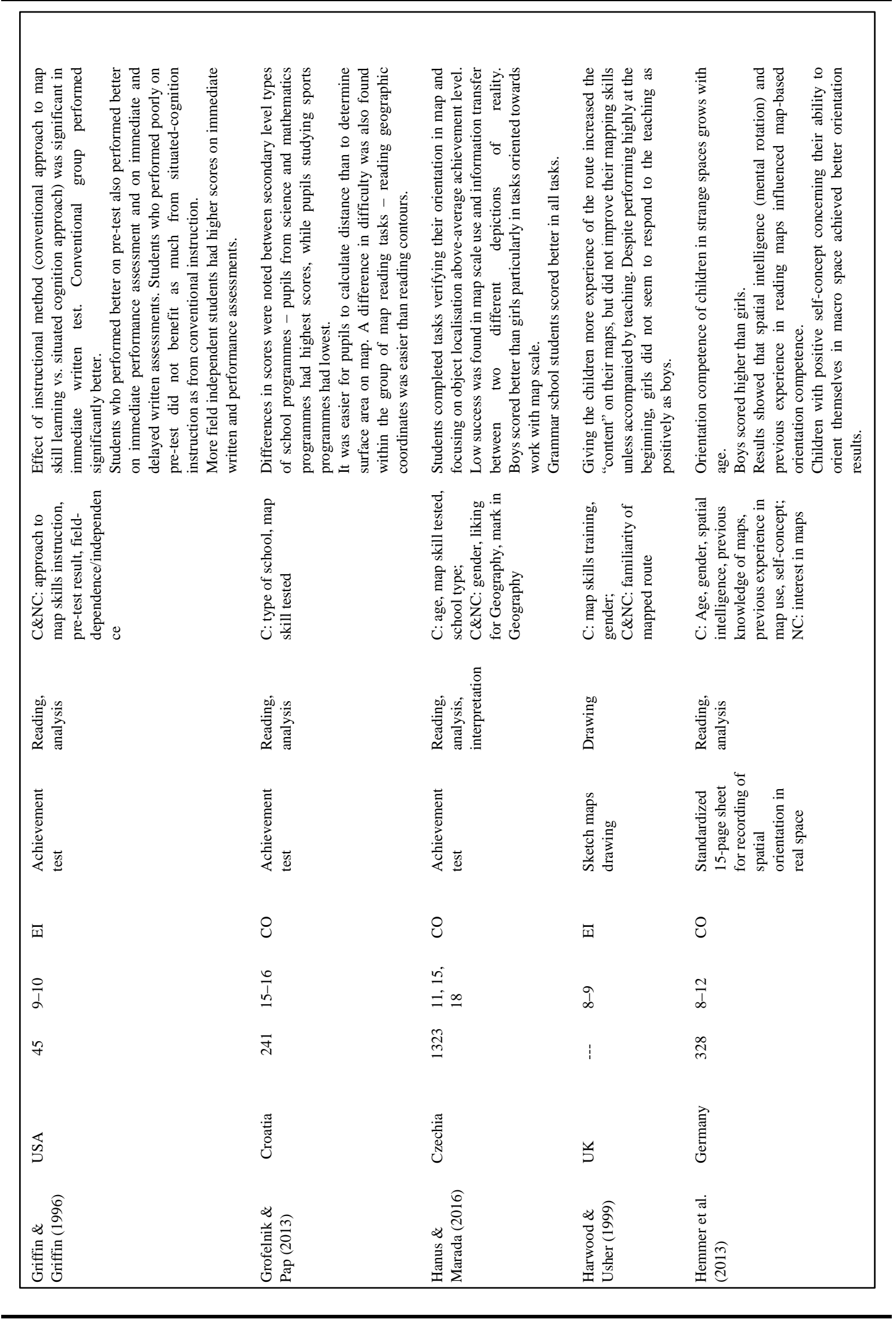




\begin{tabular}{|c|c|c|c|c|c|}
\hline 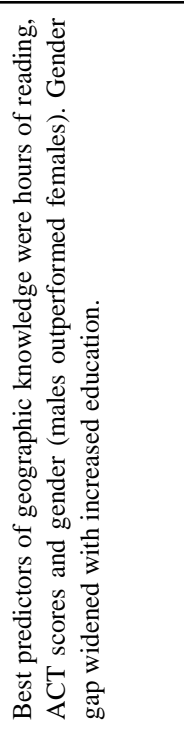 & 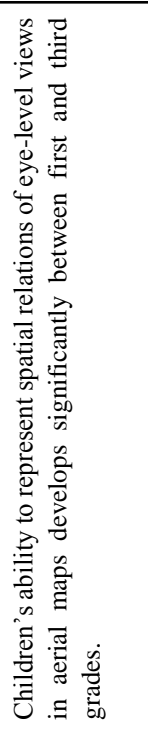 & 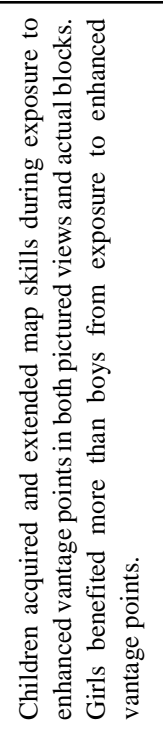 & 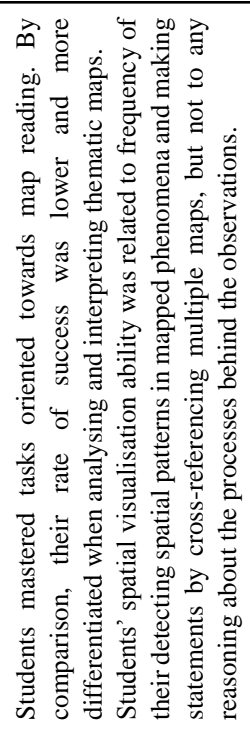 & 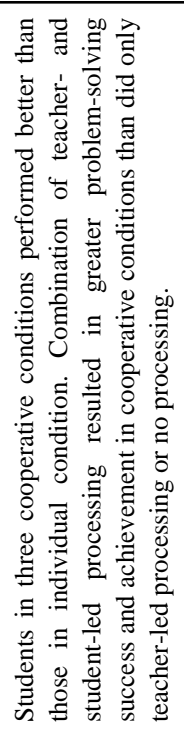 & 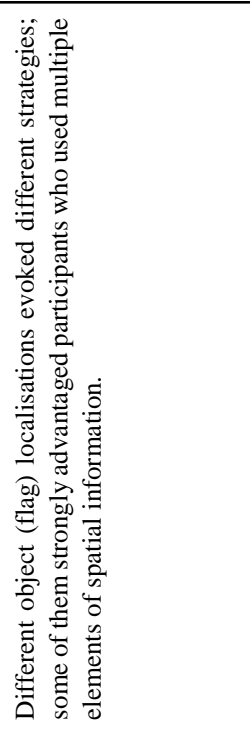 \\
\hline 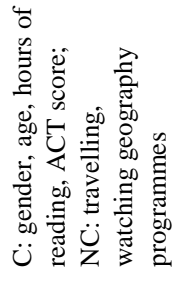 & 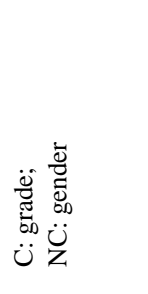 & 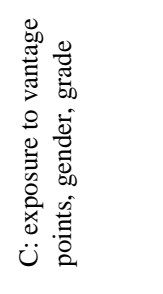 & 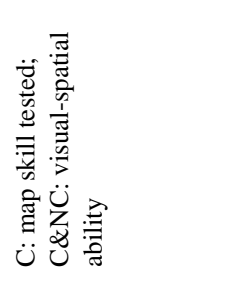 & 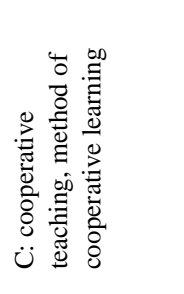 & 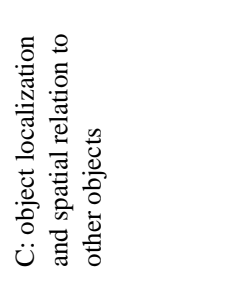 \\
\hline 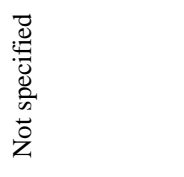 & 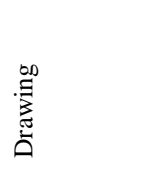 & 惫 & 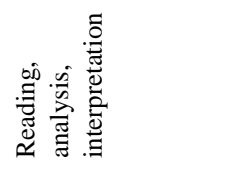 & 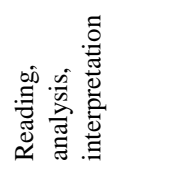 & $\begin{array}{l}\frac{n}{5} \\
\frac{2}{2} \\
\frac{\pi}{\pi} \\
\frac{\pi}{4}\end{array}$ \\
\hline 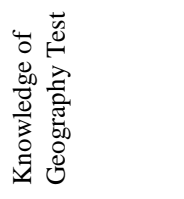 & 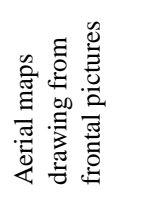 & 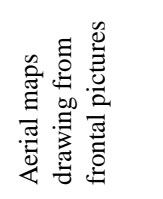 & 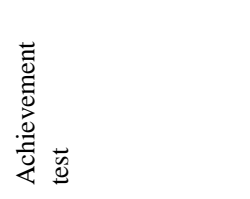 & 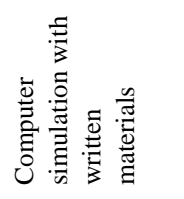 & 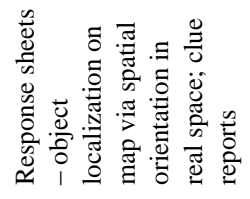 \\
\hline 8 & 8 & $\overrightarrow{\mid r}$ & 8 & $\overrightarrow{\text { II }}$ & 8 \\
\hline $\begin{array}{l}\text { P } \\
\stackrel{9}{\Omega} \\
\text { I }\end{array}$ & $\begin{array}{l}\infty \\
\tilde{b}=\end{array}$ & $\begin{array}{l}\infty \\
\tilde{b}=\end{array}=$ & $\partial$ & $\begin{array}{l}\stackrel{\oplus}{\infty} \\
\infty\end{array}$ & $\frac{0}{\alpha}$ \\
\hline 总 & 8 & $\hat{n}$ & $\vec{F}$ & $\stackrel{\infty}{+}$ & mे \\
\hline 峁 & 芯 & 芯 & $\begin{array}{l}\text { : } \\
\text { : }\end{array}$ & 芯 & 峁 \\
\hline 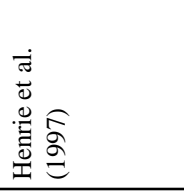 & 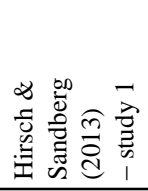 & 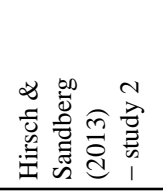 & 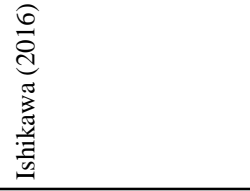 & 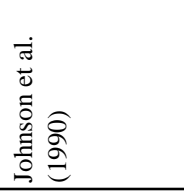 & 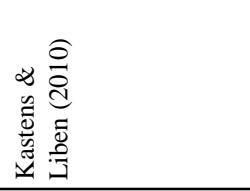 \\
\hline
\end{tabular}




\begin{tabular}{|c|c|c|c|c|c|}
\hline 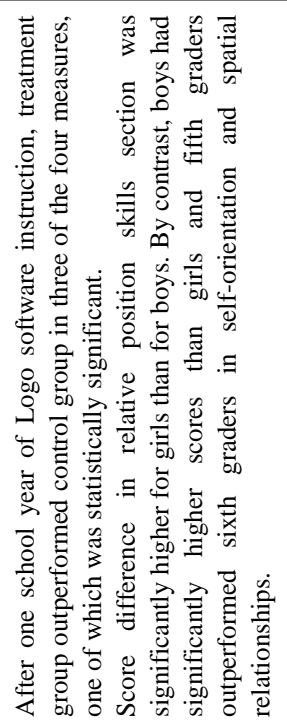 & 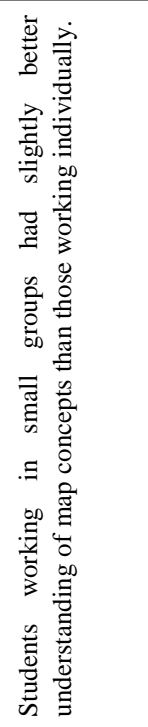 & 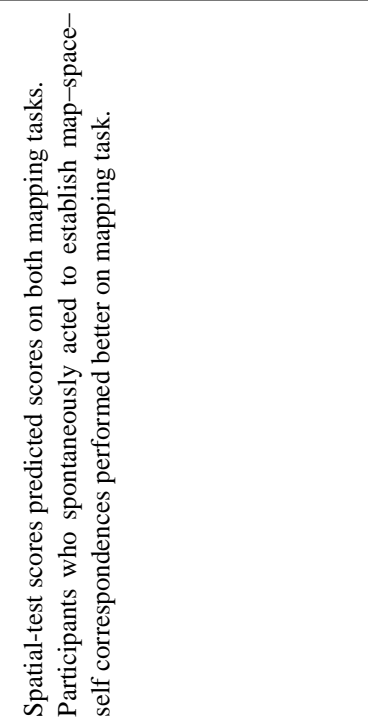 & 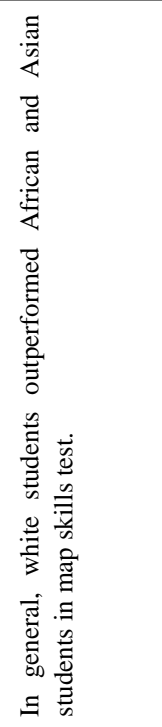 & 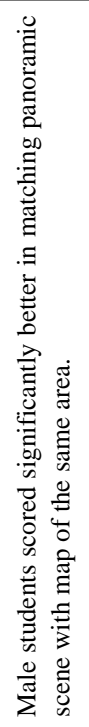 & 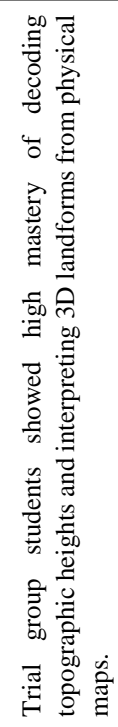 \\
\hline 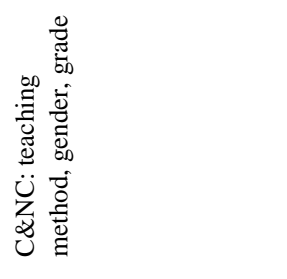 & 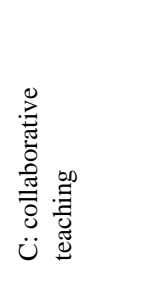 & 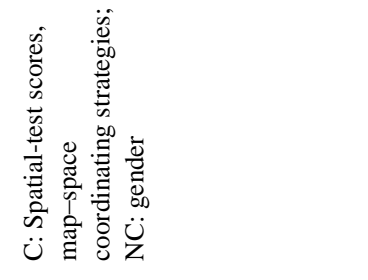 & 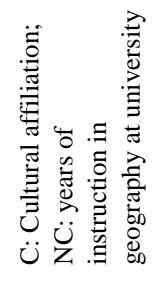 & 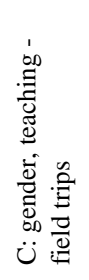 & 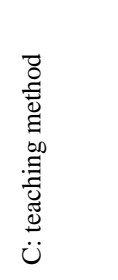 \\
\hline $\begin{array}{l}\frac{n}{5} \\
\frac{2}{3} \\
\frac{\pi}{5} \\
\frac{\pi}{4}\end{array}$ & 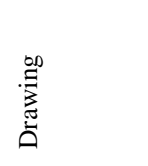 & $\begin{array}{l}\frac{0}{3} \\
\frac{2}{3} \\
\frac{a}{4}\end{array}$ & 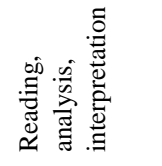 & 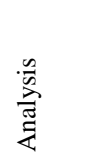 & $\begin{array}{l}\frac{n}{5} \\
\frac{2}{3} \\
\frac{\pi}{4}\end{array}$ \\
\hline 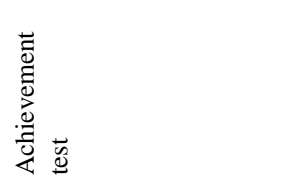 & 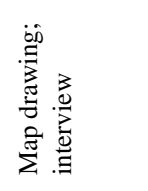 & 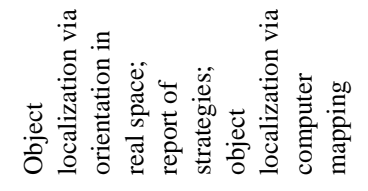 & 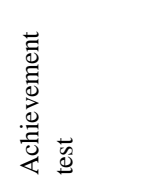 & 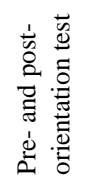 & 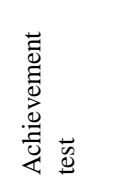 \\
\hline$\ddot{y}$ & 띠 & 8 & 8 & $\bar{I}$ & $\overrightarrow{\breve{I}}$ \\
\hline$\frac{\mathfrak{d}}{\underline{a}}$ & $\stackrel{m}{\stackrel{M}{\simeq}}$ & $\frac{\circ}{\alpha}$ & $\supset$ & $\begin{array}{l}\frac{n}{7} \\
\frac{1}{7}\end{array}$ & $\frac{\circ}{a}$ \\
\hline ڤิ & $\stackrel{f}{f}$ & q & $\hat{m}$ & 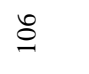 & 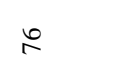 \\
\hline 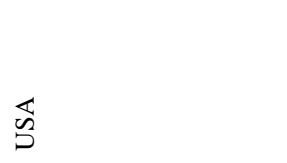 & $\begin{array}{l}\overleftrightarrow{s} \\
\qquad 5\end{array}$ & $\begin{array}{l}\overleftrightarrow{b} \\
\qquad 5\end{array}$ & 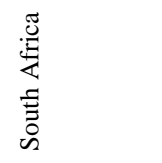 & 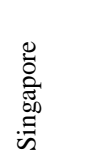 & 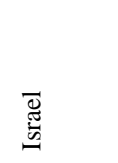 \\
\hline 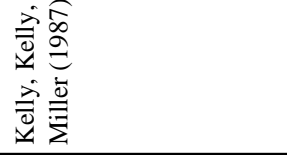 & 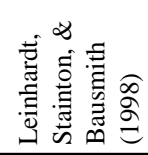 & 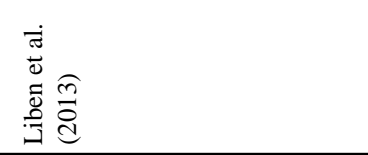 & 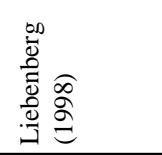 & $\begin{array}{l}\text { 高 } \\
\text { d. } \\
\text { : }\end{array}$ & 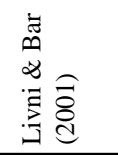 \\
\hline
\end{tabular}




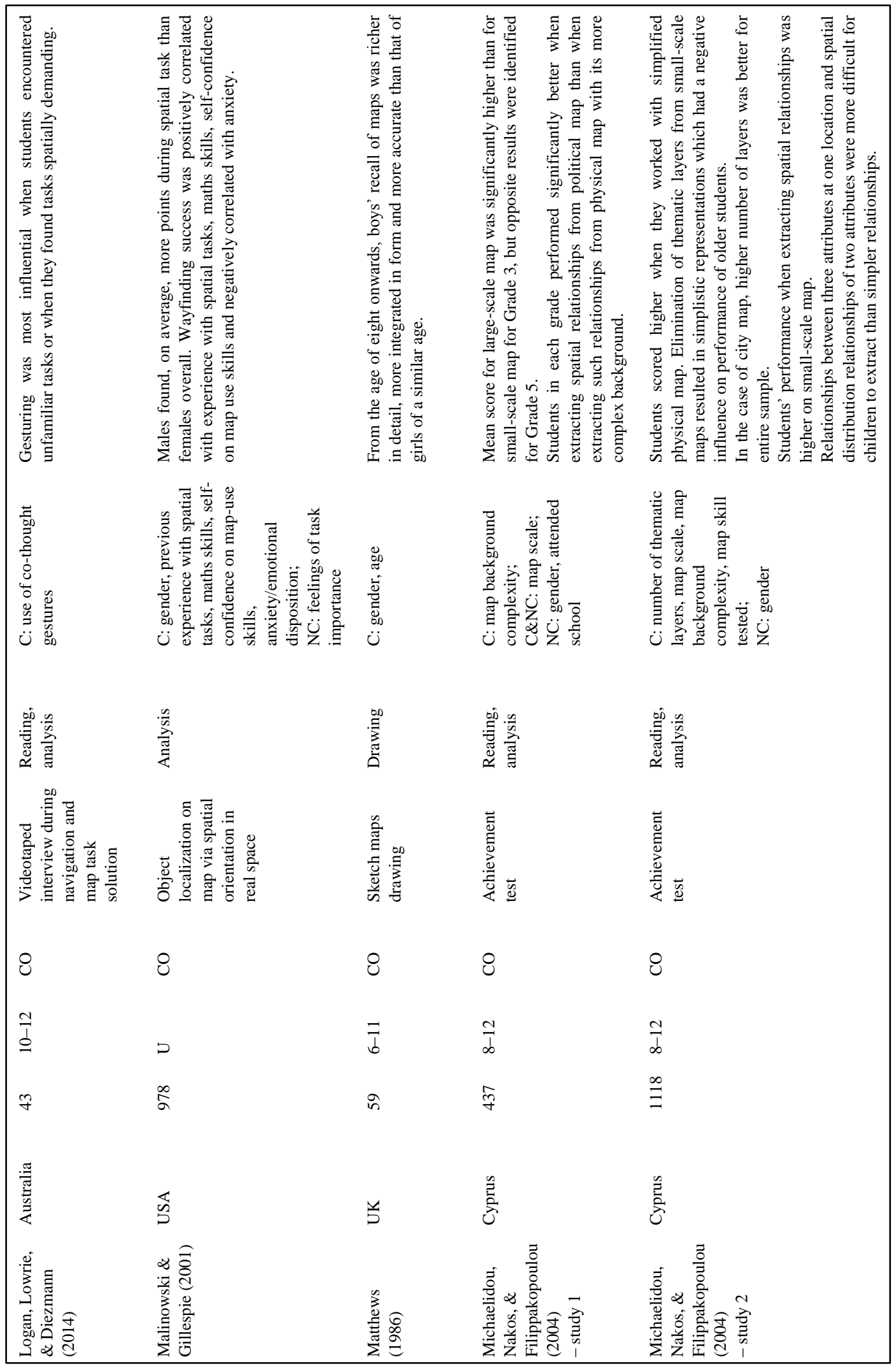




\begin{tabular}{|c|c|c|c|c|c|}
\hline 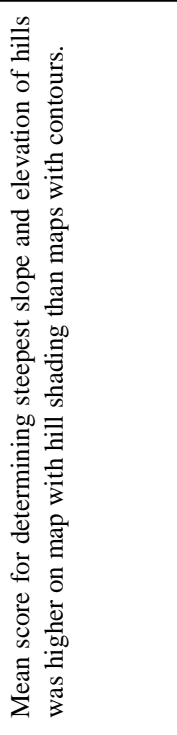 & 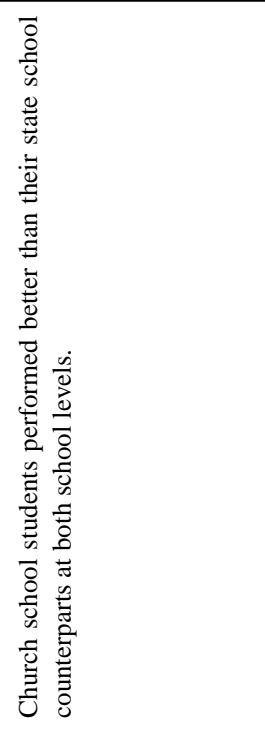 & 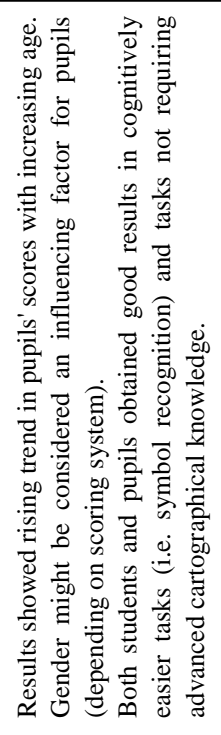 & 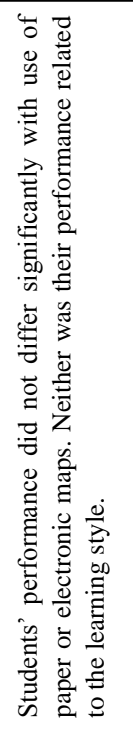 & 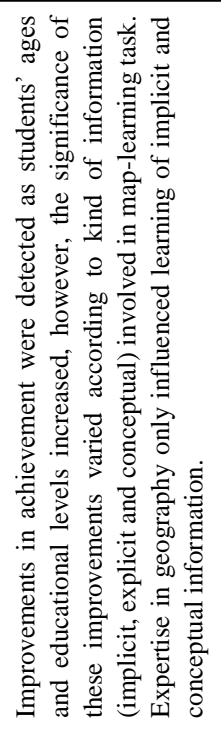 & 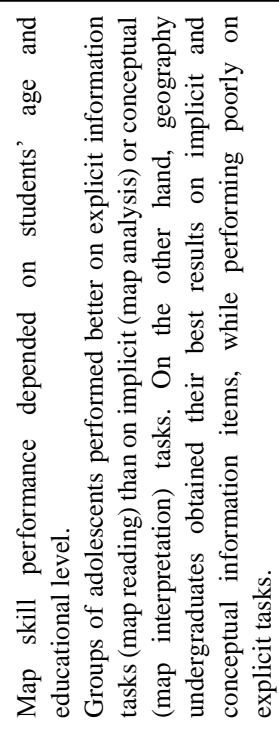 \\
\hline 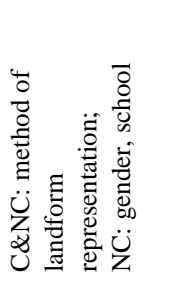 & 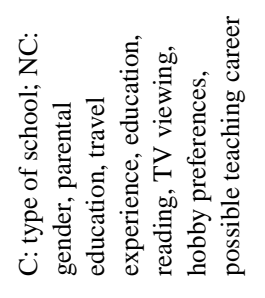 & 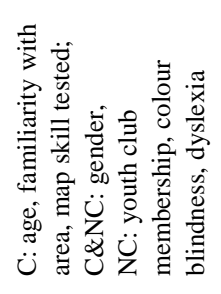 & 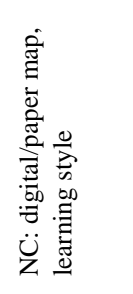 & 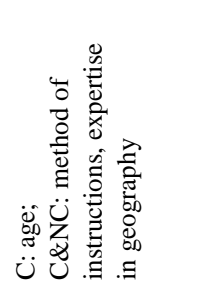 & 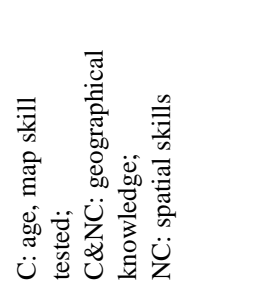 \\
\hline 竞 & 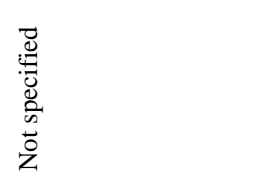 & 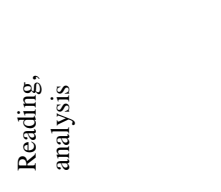 & 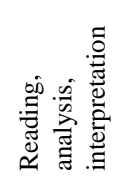 & 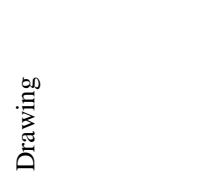 & 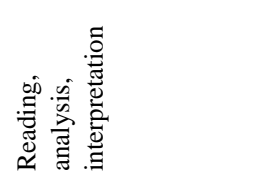 \\
\hline 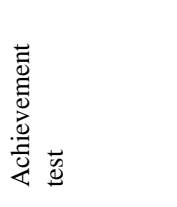 & 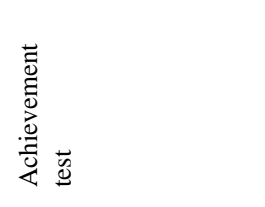 & 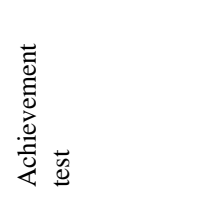 & 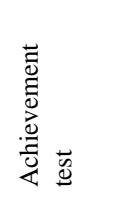 & 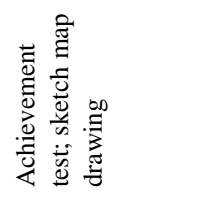 & 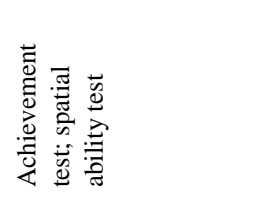 \\
\hline 8 & 8 & 8 & $\omega$ & $\vec{y}$ & $\omega$ \\
\hline$\frac{\vec{d}}{\infty}$ & $\begin{array}{l}\frac{\infty}{\beth} \\
\simeq\end{array}$ & $\stackrel{\infty}{I} \stackrel{\infty}{=}$ & D. & $\begin{array}{l}m: \\
m=\end{array}$ & 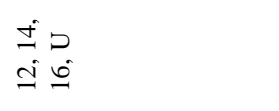 \\
\hline$\stackrel{\infty}{\gtrless}$ & $\stackrel{\infty}{m}$ & $\underset{\sim}{\sim}$ & $\stackrel{\infty}{\circ}$ & $\underset{ల}{8}$ & 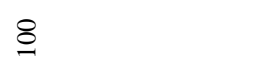 \\
\hline : & 芯 & 壱 & 兔 & $\begin{array}{l}\text { 言 } \\
\text { के }\end{array}$ & $\begin{array}{l}\text { 言 } \\
\text { की }\end{array}$ \\
\hline 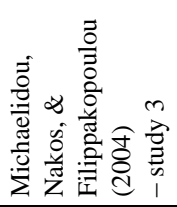 & 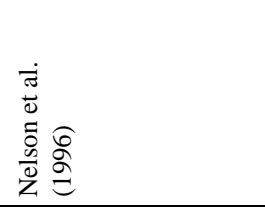 & 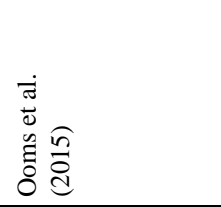 & 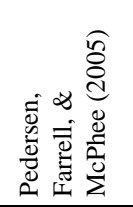 & 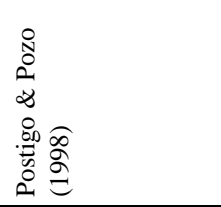 & 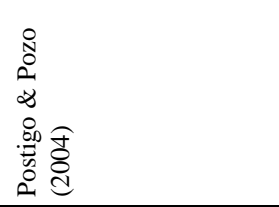 \\
\hline
\end{tabular}




\begin{tabular}{|c|c|c|c|c|c|c|}
\hline 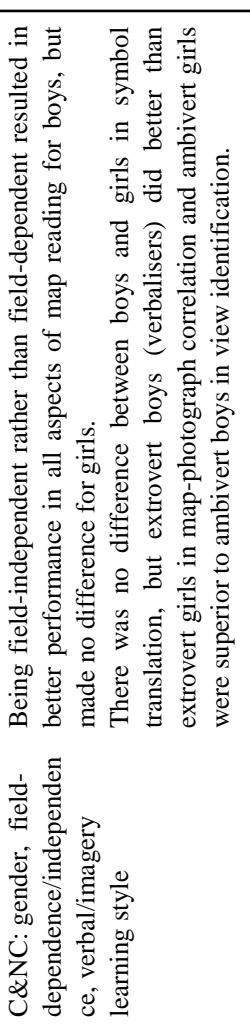 & 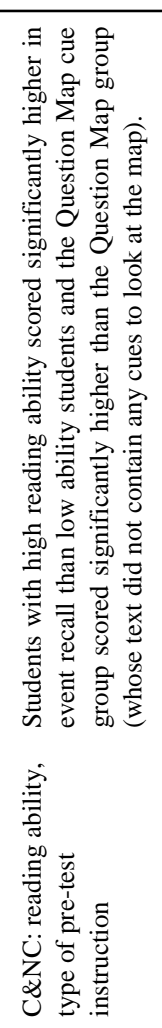 & 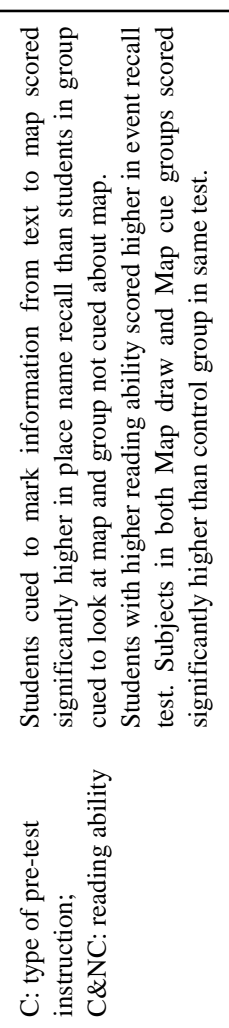 & 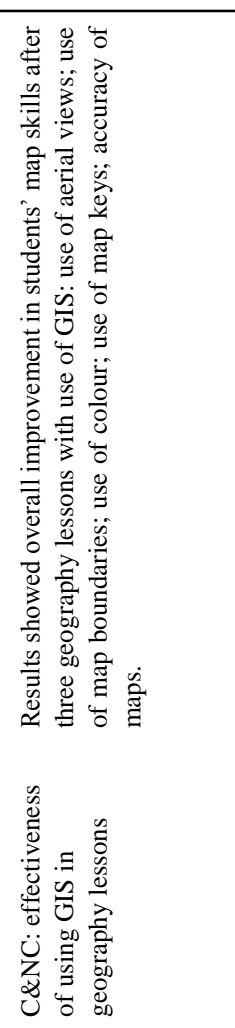 & 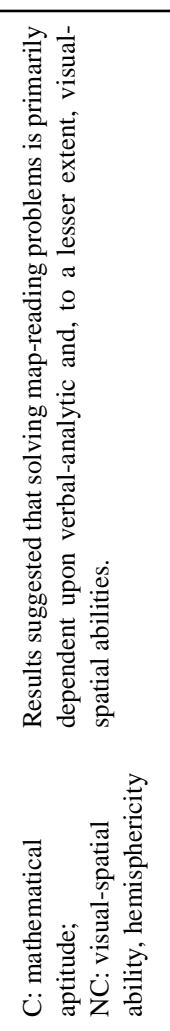 & 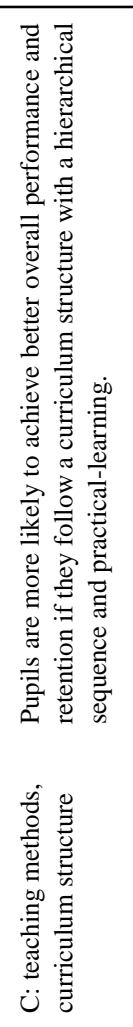 & 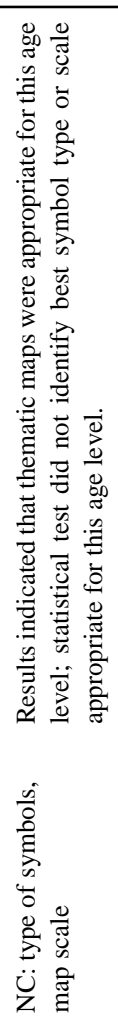 \\
\hline 苋 & 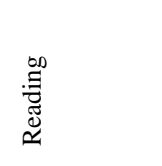 & 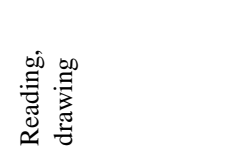 & 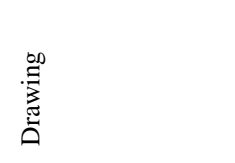 & 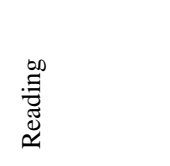 & 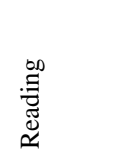 & 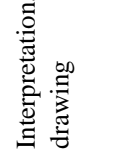 \\
\hline 䓂 & 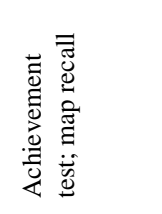 & 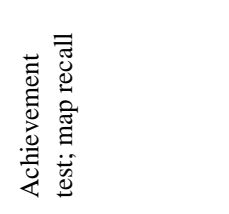 & 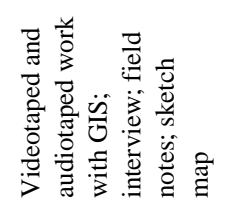 & 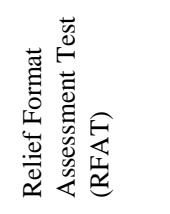 & 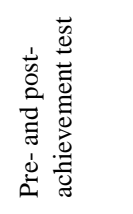 & 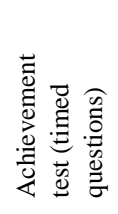 \\
\hline 8 & 可 & 可 & 可 & 8 & $\vec{I}$ & 8 \\
\hline \pm & $\frac{0}{n}$ & $\begin{array}{l}\stackrel{0}{1} \\
\underline{n}\end{array}$ & $\frac{\circ}{a}$ & D. & $\stackrel{m}{\underline{I}}$ & $\stackrel{\infty}{\sim}$ \\
\hline 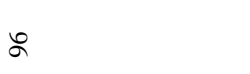 & $\infty$ & t & $\because$ & $q$ & 过 & i \\
\hline$\breve{b}$ & 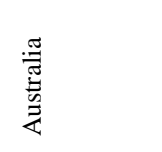 & 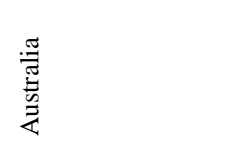 & 苑 & 苑 & 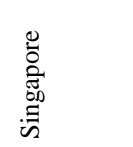 & 荗 \\
\hline 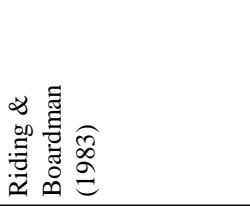 & 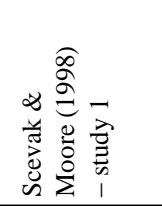 & 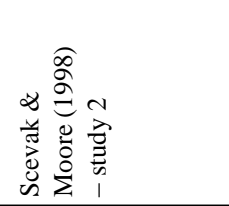 & $\begin{array}{l}\text { 高 } \\
\text { d } \\
\text { 竞 }\end{array}$ & 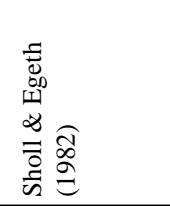 & 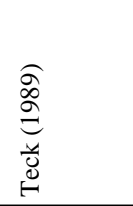 & 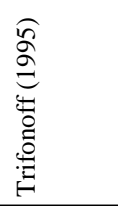 \\
\hline
\end{tabular}




\begin{tabular}{|c|c|c|c|c|}
\hline 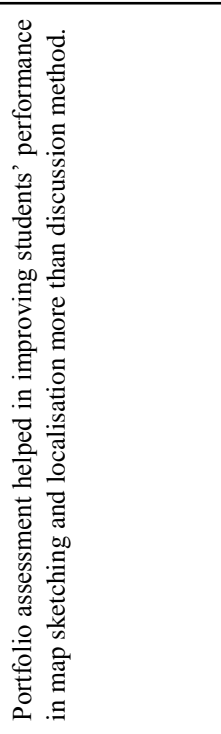 & 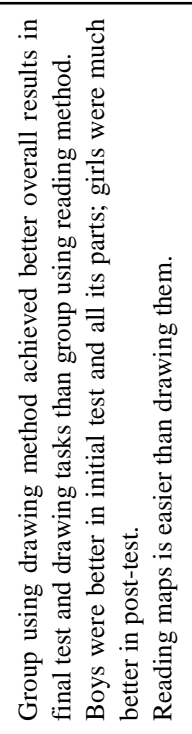 & 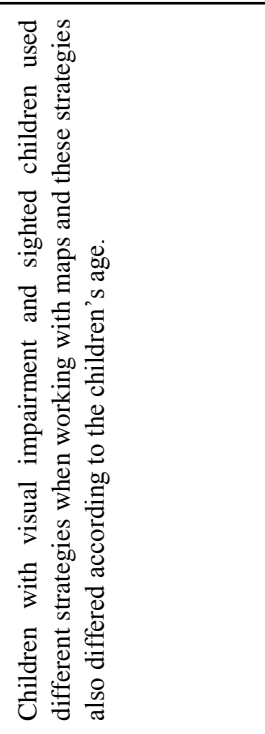 & 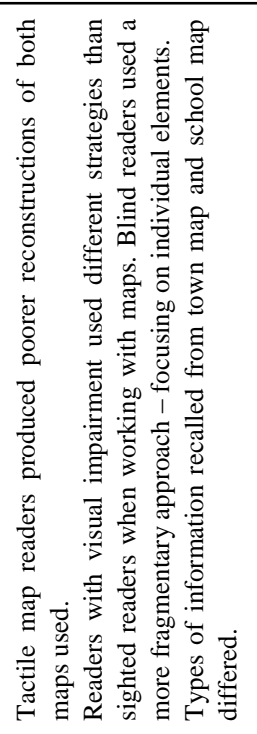 & 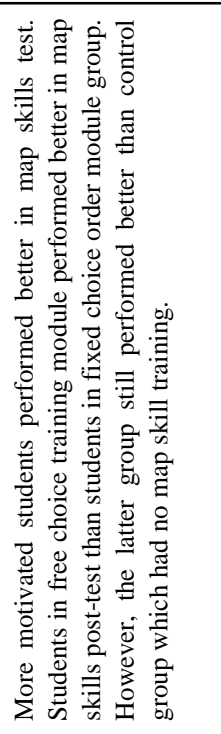 \\
\hline 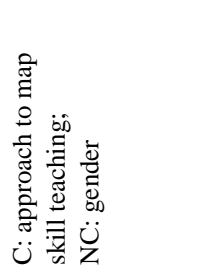 & 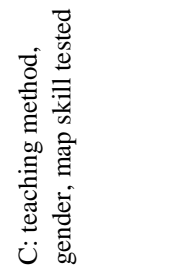 & 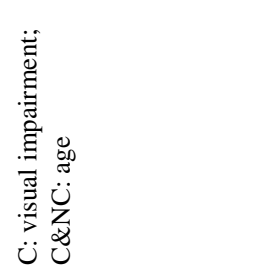 & 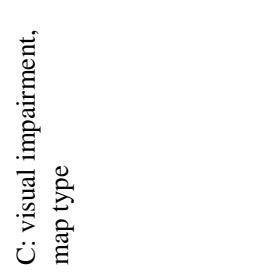 & 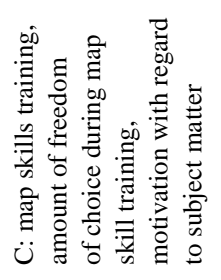 \\
\hline 㕵 & 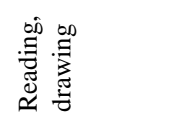 & 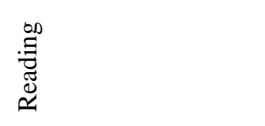 & 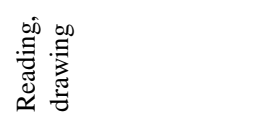 & 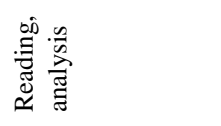 \\
\hline 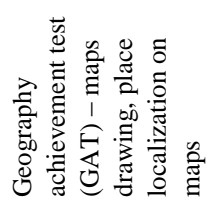 & 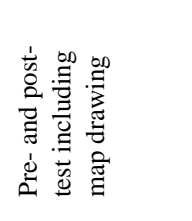 & 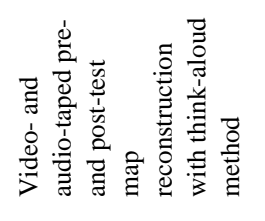 & 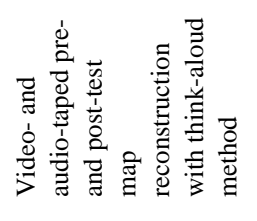 & 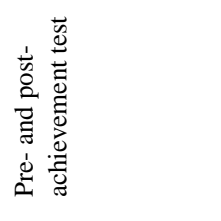 \\
\hline 可 & $\overrightarrow{\text { II }}$ & 띠 & 피 & $\overrightarrow{\underline{I}}$ \\
\hline$\frac{\infty}{1}$ & $\stackrel{\infty}{i}$ & $\frac{m}{i}$ & $\supset$ & $\stackrel{m}{\stackrel{m}{\beth}}$ \\
\hline $\bar{\Xi}$ & $q$ & $\bar{F}$ & $\underset{d}{J}$ & 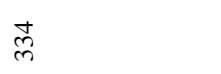 \\
\hline 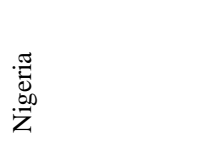 & $\begin{array}{l}\frac{\pi}{5} \\
\frac{0}{0} \\
\frac{0}{n}\end{array}$ & 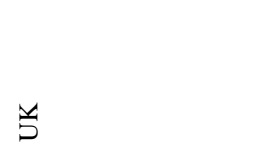 & $\breve{y}$ & 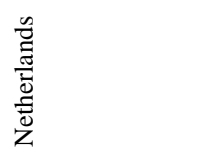 \\
\hline 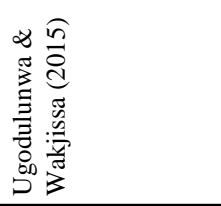 & 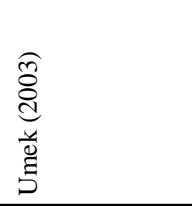 & 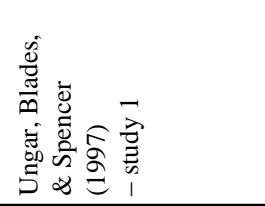 & 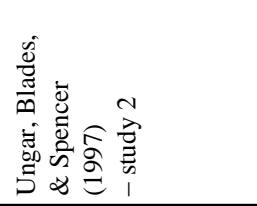 & 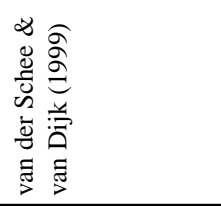 \\
\hline
\end{tabular}




\begin{tabular}{|c|c|c|c|c|}
\hline 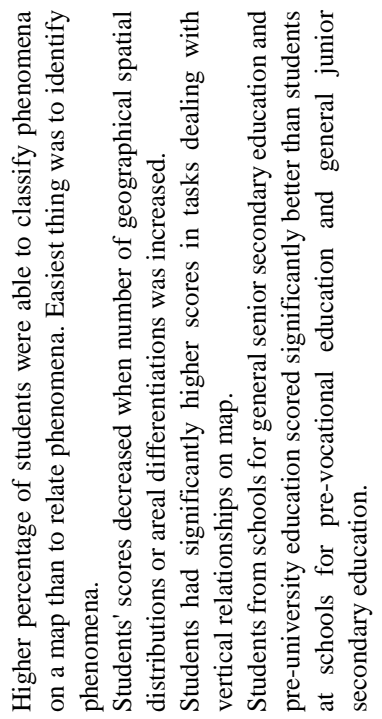 & 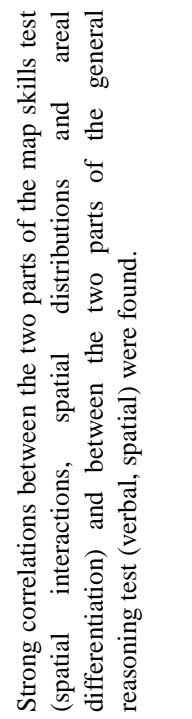 & 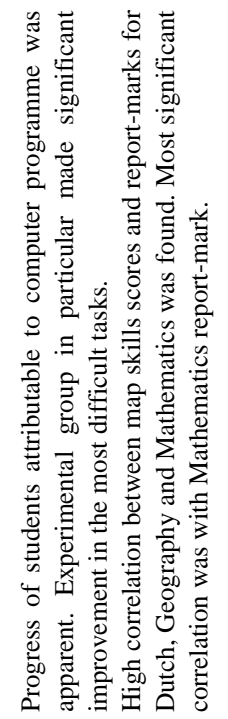 & 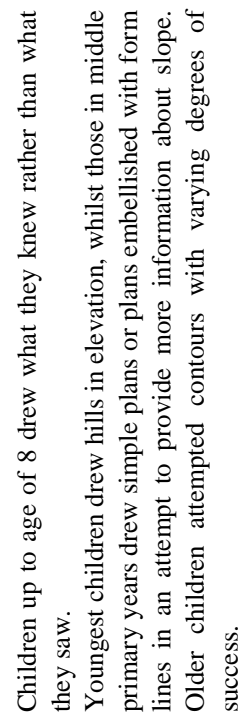 & 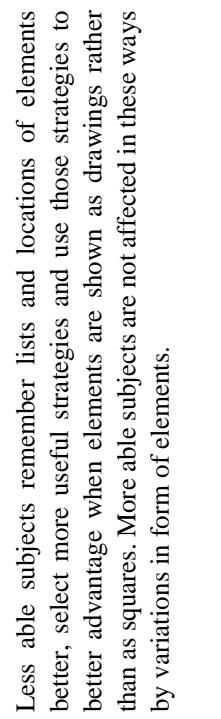 \\
\hline 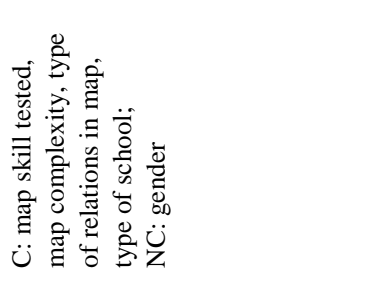 & 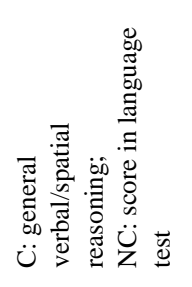 & 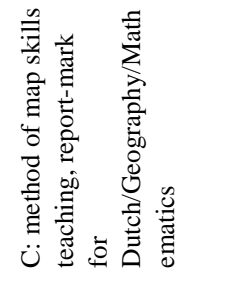 & 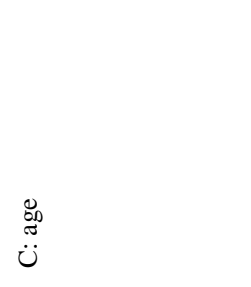 & 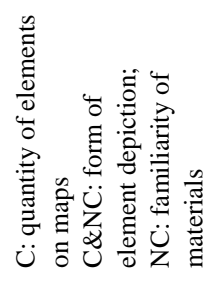 \\
\hline 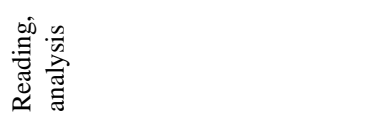 & 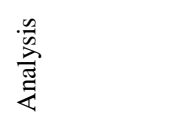 & 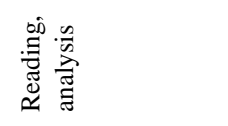 & 点 & $\begin{array}{l}\stackrel{\infty}{\Xi} \\
\stackrel{\Xi}{\Xi} \\
\simeq\end{array}$ \\
\hline 䓂 & 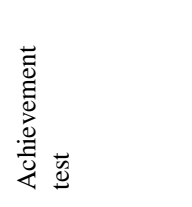 & 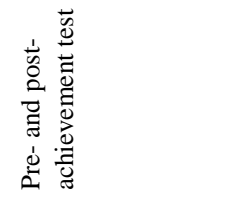 & 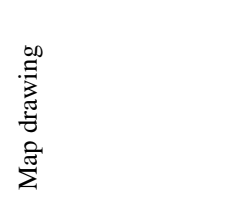 & 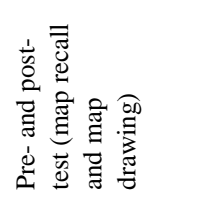 \\
\hline 8 & 8 & $\overrightarrow{\vec{y}}$ & 山 & س \\
\hline$\stackrel{m}{d}$ & $\stackrel{m}{\beth}$ & $\begin{array}{l}\stackrel{M}{I} \\
\beth\end{array}$ & $\bar{i}$ & $\bar{I}$ \\
\hline $\bar{d}$ & $\vec{n}$ & $\overrightarrow{i n}$ & $\Xi$ & $\stackrel{\infty}{\simeq}$ \\
\hline 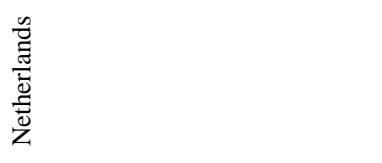 & 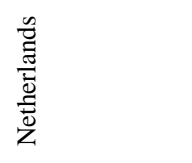 & 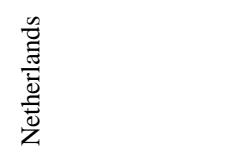 & 光 & s. \\
\hline 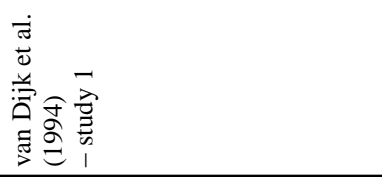 & 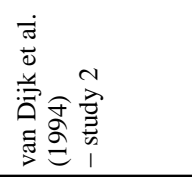 & 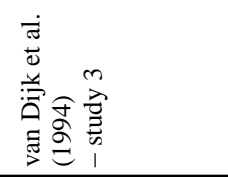 & 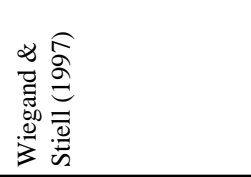 & 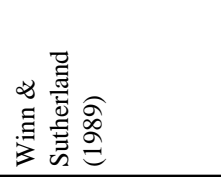 \\
\hline
\end{tabular}

